\title{
Energy and Momentum Lost to Wake Eddies and Lee Waves Generated by the North Equatorial Current and Tidal Flows at Peleliu, Palau
}

By T.M. Shaun Johnston, Jennifer A. MacKinnon, Patrick L. Colin, Patrick J. Haley Jr., Pierre F.J. Lermusiaux, Andrew J. Lucas, Mark A. Merrifield, Sophia T. Merrifield, Chris Mirabito, Jonathan D. Nash, Celia Y. Ou, Mika Siegelman, Eric J. Terrill, and Amy F. Waterhouse 
ABSTRACT. The North Equatorial Current (NEC) transports water westward around numerous islands and over submarine ridges in the western Pacific. As the currents flow over and around this topography, the central question is: how are momentum and energy in the incident flow transferred to finer scales? At the south point of Peleliu Island, Palau, a combination of strong NEC currents and tides flow over a steep, submarine ridge. Energy cascades suddenly from the NEC via the $1 \mathrm{~km}$ scale lee waves and wake eddies to turbulence. These submesoscale wake eddies are observed every tidal cycle, and also in model simulations. As the flow in each eddy recirculates and encounters the incident flow again, the associated front contains interleaving temperature $(T)$ structures with 1-10 m horizontal extent. Turbulent dissipation $(\varepsilon)$ exceeds $10^{-5} \mathrm{~W} \mathrm{~kg}^{-1}$ along this tilted and strongly sheared front. A train of such submesoscale eddies can be seen at least $50 \mathrm{~km}$ downstream. Internal lee waves with $1 \mathrm{~km}$ wavelengths are also observed over the submarine ridge. The mean form drag exerted by the waves (i.e., upward transport of eastward momentum) of about $1 \mathrm{~Pa}$ is sufficient to substantially reduce the westward NEC, if not for other forcing, and is greater than the turbulent bottom drag of about $0.1 \mathrm{~Pa}$. The effect on the incident flow of the form drag from only one submarine ridge may be similar to the bottom drag along the entire coastline of Palau. The observed $\varepsilon$ is also consistent with local dissipation of lee wave energy. The circulation, including lee waves and wake eddies, was simulated by a datadriven primitive equation ocean model. The model estimates of the form drags exerted by pressure drops across the submarine ridge and due to wake eddies were found to be about 10 times higher than the lee wave and turbulent bottom drags. The ridge form drag was correlated to both the tidal flow and winds while the submesoscale wake eddy drag was mainly tidal.

IN PLAIN WORDS. In the western Pacific, the North Equatorial Current encounters islands and submarine ridges and is forced to go around or over these obstacles. This incident flow combines with tidal flow at the south point of Palau to produce wake eddies and lee waves, which remove energy and momentum via turbulence and drag. Frictional bottom drag is exceeded by the form drag (changes in pressure as the flow passes over topography) from lee waves transporting momentum and from wakes that create pressure drops across the topography. Turbulence is elevated at the seafloor and also at the front, separating the wake from the incident flow. All of these processes occur within about $1 \mathrm{~km}$ of the headland and the adjacent submarine ridge. We used a variety of measurements and modeling techniques to further understanding of the effects of major current encounters with steep topography.

\section{INTRODUCTION}

When ocean currents encounter topography, the resultant wake facilitates a loss of both energy and momentum from the incident flow. At the numerous islands and ridges in the western Pacific, the sum of such wake effects may produce an important, if poorly understood, drag on regional currents. Better prediction of the currents and their roles in low-latitude heat and freshwater distribution requires an improved physical understanding of the underlying dynamics.

At least two different processes can cause island wakes to develop, wake eddies and lee waves (Warner and MacCready, 2009). Wake eddies, or vortices, are produced by flow separation when rapid currents are unable to round coastal headlands. Because the topography exerts a frictional force on the flow via turbulent drag, the flow slows in a narrow adjacent boundary layer, while the flow outside the boundary layer con- tinues and eventually recirculates, forming the wake eddy (Kundu and Cohen, 2002). In contrast, lee waves are formed where stratified water moves up and over sloping underwater ridges (Gill, 1982). They are analogous to atmospheric waves sometimes observed in the lee of mountains, noticeable by their associated lenticular cloud patterns. The breaking of these atmospheric lee waves causes clear air turbulence noted by airline passengers. For ocean wakes, energy lost from the incident flow hitting topography is typically transferred to smaller-scale motions (wake eddies or lee waves) that in turn can become unstable and break down into turbulent mixing.

The numerous islands and submarine ridges of the Pacific island nation of Palau provide a particularly good natural laboratory for observing and understanding wake effects. In this contribution to the special issue of Oceanography on the Flow Encountering Abrupt Topography initiative, we compare and contrast processes at the north and south points of Palau (Velasco Reef and Peleliu Island). Palau's topography rises steeply into the energetic North Equatorial Current, and open ocean conditions are noted at the reef edge at hourly to interannual timescales (Qiu et al., 2015; Schönau and Rudnick, 2015; Colin, 2018; Schramek et al., 2018, and 2019, in this issue). Velasco Reef is a submerged reef in the north, sufficiently shallow to block the North Equatorial Current (NEC). It is separated from the main lagoon area that lies east of the island by a deep, narrow channel that is open to oceanic flows (Zeiden et al., 2019), where westward flow is also noted (Figure 1a). The lagoon then extends southward, uninterrupted until reaching the south point of Peleliu Island, where flow can again proceed westward.

At the south point of Peleliu, near the flow separation point, we observed a dramatic cascade of kinetic and potential energy from the NEC (at mesoscales with 
lengths $>100 \mathrm{~km}$ ) into $1 \mathrm{~km}$ lee waves and submesoscale wake eddies (typically $<10 \mathrm{~km}$; Figure 1), then into fronts at scales of 1-10 m and finally into turbulent dissipation at centimeter to millimeter scales. Bottom drag friction brings the flow to zero at the seafloor, while form drag arises due to changes in pressure as the flow passes the topography, for example, a pressure differential across a point due to wake eddies (Warner and MacCready, 2009), a hydraulic jump (Moum and Nash, 2000), or lee waves (Gill, 1982). Even small topographic changes can remove a considerable amount of energy and momentum from the incident flow through dissipation and drag (Moum and Nash, 2000). When such lee wave drag is parameterized and included in HYbrid Coordinate Ocean Model (HYCOM) simulations used for Navy global ocean forecasting, not only are deep velocities and stratification greatly affected, but also surface velocities, albeit to a lesser extent (Arbic et al., 2019, in this issue).

At the north point of Palau (Velasco; upper green square in Figure 1a), a combination of tidal and mean flows produces a broadband wake that ranges from submesoscale, $\sim 1 \mathrm{~km}$ diameter, tidally mediated eddies (MacKinnon et al., 2019) to $\sim 70 \mathrm{~km}$ diameter island-scale eddies (Zeiden et al., 2019). These eddies are preferentially cyclonic (counterclockwise) due to the mean westward flow. Similarly, at the south point of Peleliu, we expect anticyclonic (clockwise) eddies with the predominantly westward flow at the meso- and submesoscale. The situation at the south point is complicated by tidal flow, which is comparable to the $0.5 \mathrm{~m} \mathrm{~s}^{-1}$ speed of the NEC here (Figure 1). During our measurements, the combined incident flow often varies from $0-1 \mathrm{~m} \mathrm{~s}^{-1}$ westward over a semidiurnal period, leading to an intense anticyclonic wake set up on a tidal timescale (Figure 2). To the best of our knowledge, wakes arising from such a combination of oscillating and mean flow have been quantified only by MacKinnon et al. (2019), which is quite surprising because a combination of mean and oscillating flows occurs at many headlands. Indeed, a broad spectrum of eddying wakes observed at the north point of Palau arises from interannual and monthly variability of the NEC combined with oscillating flows at near-inertial and tidal periods (Johnston et al., 2019, in this issue; MacKinnon et al.,
2019; Merrifield et al., 2019, in this issue; Qiu et al., 2019, in this issue; Rudnick et al., 2019, in this issue; Siegelman et al., 2019, in this issue; Simmons et al., 2019, in this issue; Zeiden et al., 2019).

The strength of an eddying wake is measured in part by the Rossby number (Ro), which is the ratio of the eddy's rotation (or vorticity) to Earth's rotation (Rudnick et al., 2019, in this issue): Ro $=\zeta / f=\left(\partial_{x} v-\partial_{y} u\right) / f$, where $f$ is the Coriolis frequency and distance $(x, y)$ and currents $(u, v)$ are positive eastward and northward. Small scale $(\sim 1 \mathrm{~km}$ diameter) high vorticity (Ro $\sim 30)$ wake eddies generated very near the separation point are strongly influenced by oscillating currents, such as tides (MacKinnon et al., 2019) and inertial motions (Siegelman et al., 2019, in this issue). Farther downstream, a mesoscale wake is observed with a lateral scale of $\sim 70 \mathrm{~km}$, comparable to the size of the topography (in this case, Velasco Reef; Zeiden et al., 2019). During periods of westward flow, the observed cyclonic (anticlockwise) wake had an average Ro $=0.3$ and exceeded 1 during periods of strong flow. The relationship between the submeso- and mesoscale wakes is not yet clear, but the submesoscale eddies can decay downscale into
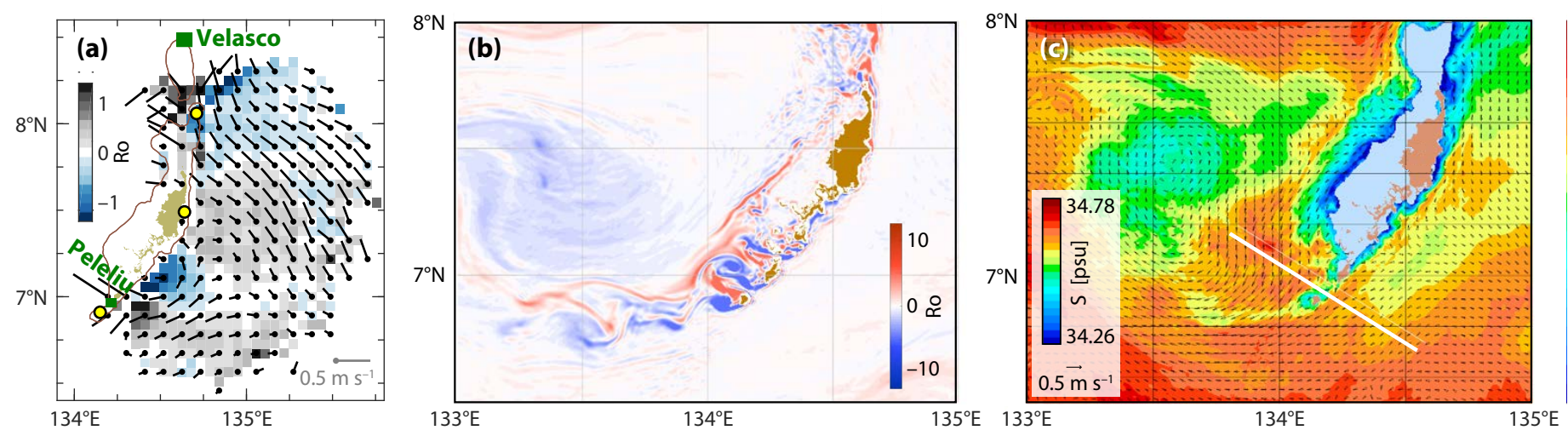

FIGURE 1. (a) Mean currents and Rossby number (Ro) from HF radar over 33 hours around 12:00 UTC on December 9, 2016, during survey C of the Flow Encountering Abrupt Topography initiative. Only every other velocity vector is plotted. Radars are located at Kayangel Island, Melekeok, and Angaur Island (yellow dots from north to south). The $800 \mathrm{~m}$ isobath is contoured (brown). The scale vector (gray) shows a $0.5 \mathrm{~m} \mathrm{~s} \mathrm{~s}^{-1}$ eastward current. The focus of this paper is the south point of Peleliu Island (southern green box), which is compared to similar work at the north point of Velasco Reef (northern green box). From Kayangel to Peleliu, the North Equatorial Current (NEC) must flow around the main lagoon area of Palau either (1) through the deep channels between Kayangel and Velasco, (2) through the deep channel between Peleliu and Angaur, or (3) around the north point of Velasco. (b) MIT-MSEAS model simulated vorticity from December 12, just after survey C, shows an island-scale wake eddy with Ro $\sim 0.2-1.2$, while Ro 1-15 arise from flow past Peleliu and Angaur Islands and are found on the periphery of the larger eddy. (c) At $70 \mathrm{~m}$ depth on December 11, the model simulations show incident westward NEC flow splits northward and southward at the east coast, flows westward past Angaur and Peleliu, and entrains relatively low salinity $(S)$ coastal water into the wake eddy. The diagonal transect (white line) through the channel between Angaur and Peleliu is shown in Figure 7. 
turbulence or coalesce into mesoscale eddies (Rudnick et al., 2019, in this issue; Zedler et al., 2019, in this issue).

Using a combination of observations and modeling over different times, we document the incident flow and the removal of energy and momentum when the flow encounters topography, and the subsequent formation of wake eddies and lee waves. Considerable form drag is noted. We conclude by discussing the local importance and broader relevance of these topographic effects on flow.

\section{METHODS}

\section{Time Series}

High-frequency (HF) radar stations were placed at Kayangel, Melekeok, and Angaur to measure the incident flow off the east coast of Palau (Figure 1a; Merrifield et al., 2019 , in this issue). Data are centered on 12:00 UTC December 9, 2016, and averaged over 33 hours to remove tides. The averaging interval is somewhat longer than one day and extends into frequencies with low variance (Figure 5d in Rudnick et al., 2019, in this issue), but does not exclude inertial motions with periods of about four days. All times and dates are in Coordinated Universal Time (UTC).

We used a combination of up to four acoustic Doppler current profilers (ADCPs), moored in bottom landers, to measure currents on the east/ upstream (site E), south (site S), and west/downstream (sites $\mathrm{W}$ and $\mathrm{N}$ ) coasts of Peleliu (Figure 2). These Teledyne RDI 500/1000 kHz Sentinel V20/V50 instruments provided coverage of most of the water column and were deployed in Sea Spider tripods at the 20-25 m isobath from September 22, 2016, to April 4, 2017. The flow near the bottom was almost always in the same direction as the flow aloft, with muted magnitude. Therefore, we describe the depthmean flow. The steep slopes precluded deeper placement of the instruments, but the $200 \mathrm{~m}$ isobath is $<500 \mathrm{~m}$ away. We deployed these instruments from the Coral Reef Research Foundation's $12 \mathrm{~m}$ research catamaran Kemedukl.

\section{Surveys}

Spatial surveys of incident and downstream flow were made over the submarine ridge and up to $3 \mathrm{~km}$ from the south point of Peleliu on October 31, November 5, and December 9, 2016 (surveys $A, B$, and $C$ ). The focus was mostly on wake eddies and lee waves of $1 \mathrm{~km}$ scale generated at the point and the submarine ridge. From October 13 to October 18, 2015 (survey D), broader coverage was obtained up to $50 \mathrm{~km}$ downstream. These surveys were not repeated and did not resolve tidal signals, which was the pur- pose of the moorings and HF radar (see later discussion). Table 1 summarizes the observations from these spatial surveys and the time series. Each survey is described below.

On surveys A-C, currents were measured from Kemedukl with a polemounted Teledyne RDI $300 \mathrm{kHz}$ Workhorse ADCP. The transducer head was at a water depth of $1 \mathrm{~m}$. Data were obtained to a depth of $80 \mathrm{~m}$ and averaged over one minute. Global positioning system (GPS) data were obtained from a Simrad HS80A differential GPS compass
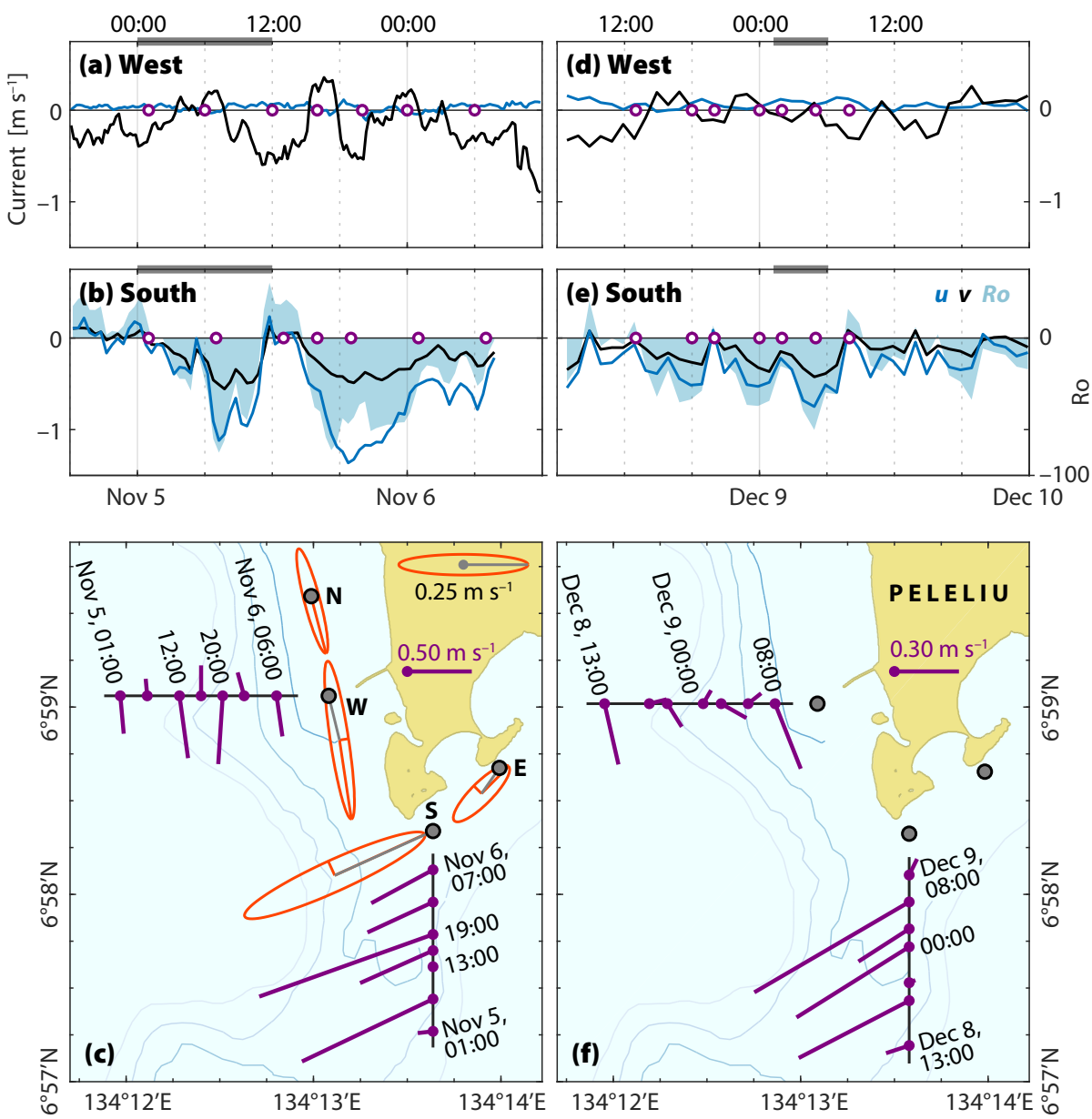

FIGURE 2. Time series during survey B of westward ( $u$, blue line) and northward ( $v$, black line) velocity at mooring sites (a) W and (b) S, located in (c). Rossby number (Ro) is calculated from the difference in velocities at $\mathrm{S}$ and $\mathrm{W}$ and shaded in light blue with the axis on the right. The gray bar on the top axis denotes the duration of survey B, detailed in Figure 5. (c) The principal axes of the total flow over the whole mooring record (with the time mean removed) are plotted as ellipses at the tip of the gray vector representing the mean flow at mooring sites $\mathrm{E}, \mathrm{S}, \mathrm{W}$, and $\mathrm{N}$ (gray dots). Isobaths are contoured in blue at $200,400,600$, and $800 \mathrm{~m}$. Velocity vector time series for sites W and S in purple (time of selected vectors noted with purple dots in Figure 2a,b) show the mean flow and tidal flow combining for maximum westward flow at site $\mathrm{S}$ and producing a wake eddy. Scales for the $0.25 \mathrm{~m} \mathrm{~s}^{-1}$ eastward mean current vector (gray), $0.25 \mathrm{~m} \mathrm{~s}^{-1}$ semi-major axis of the current ellipse, and $0.5 \mathrm{~m} \mathrm{~s}^{-1}$ vector for the time series (purple) are shown. (d-f) As above, but for survey C. Note the change of vector scale. 


\begin{tabular}{|c|c|c|c|c|c|c|}
\hline & MOORINGS & HF RADAR & SURVEY A & SURVEY B & SURVEY C & SURVEY D \\
\hline PURPOSE(S) & $\begin{array}{l}\text { - Incident Flow } \\
\text { - Wake Eddy }\end{array}$ & $\begin{array}{l}\text { - Incident Flow } \\
\text { - Ro }\end{array}$ & $\begin{array}{l}\text { - Lee Wave } \\
\cdot C_{d}\end{array}$ & $\begin{array}{l}\cdot \varepsilon \\
\text { - Wake Eddy }\end{array}$ & $\begin{array}{l}\text { - Lee Wave } \\
\text { - Wake Eddy }\end{array}$ & - Downstream Eddies \\
\hline DATE & $\begin{array}{l}\text { Sep 22, 2016- } \\
\text { Apr 4, } 2017\end{array}$ & Dec 9, 2016 & Oct 31, 2016 & Nov 5, 2016 & Dec 9, 2016 & Oct 13-18, 2015 \\
\hline EXTENT & $1.5 \mathrm{~km}$ & $100 \mathrm{~km}$ & $3 \mathrm{~km}$ & $3.5 \mathrm{~km}$ & $3.5 \mathrm{~km}$ & $50 \mathrm{~km}$ \\
\hline INSTRUMENTS & - ADCP & - HF Radar & $\begin{array}{l}\text { - ADCP } \\
\text { - ROSS } \\
\text { - VMP } \\
\text { - T Chain } \\
\text { - Wirewalker }\end{array}$ & $\begin{array}{l}\text { - ADCP } \\
\text { - ROSS } \\
\text { - VMP } \\
\text { - T Chain }\end{array}$ & $\begin{array}{l}\text { - ADCP } \\
\text { - UCTD }\end{array}$ & $\begin{array}{l}\text { - ADCP } \\
\text { - SeaSoar }\end{array}$ \\
\hline
\end{tabular}

with a root-mean-squared heading accuracy of $0.5^{\circ}$. The GPS and ADCP data were merged after the surveys.

Surveys A and B used an array of instruments to examine the wake eddy and front over 12 hours (see later sections): a towed thermistor chain, a Robotic Oceanographic Surface Sampler (ROSS), a drifting profiling Wirewalker, and a Rockland Scientific Vertical Microstructure Profiler 200 (VMP). The thermistor chain consisted of a $10 \mathrm{~m}$ long line towed from Kemedukl, with eight RBR Solo thermistors, two RBR Concerto CTD instruments, and a weight at the bottom. It was used at survey speeds of $0.5-1 \mathrm{~m} \mathrm{~s}^{-1}$ and provided $1 \mathrm{~m}$ horizontal resolution of temperature $(T)$ and salinity $(S)$ in the near-surface ocean.

ROSS cruises autonomously at 2-3 $\mathrm{m} \mathrm{s}^{-1}$ (Nash et al., 2017) with a towed thermistor string, a Teledyne RDI $300 \mathrm{kHz}$ ADCP, and a Hemisphere Vector V102 differential GPS compass. ROSS surveyed along with Kemedukl, allowing for simultaneous measurements of submesoscale wake eddies at two nearby locations.

A freely drifting ocean wave-powered Wirewalker profiler (Pinkel et al., 2011; Lucas et al., 2016) was deployed during survey A off the east coast and profiled as it drifted rapidly westward. The Wirewalker was equipped with GPS in the surface buoy, an RBR Concerto CTD, and a Nortek Signature $1 \mathrm{MHz}$ Aquadopp current meter.

The VMP is a loosely tethered microstructure profiler equipped with two shear probes that permit calculation of turbulent kinetic energy dissipation $(\varepsilon)$ following standard practices in $1 \mathrm{~m}$ bins (Moum et al., 1995). The VMP also has $T$, conductivity $(C)$, and pressure sensors. The instrument was deployed off the stern of Kemedukl to 50-70 m depth every 1-2 minutes at a fall rate of $0.6-0.9 \mathrm{~m} \mathrm{~s}^{-1}$ with a horizontal resolution of about $100 \mathrm{~m}$. The upper $1-2 \mathrm{~m}$ is excluded because of the ship's wake.

Survey C ventured farther offshore than surveys A and B to examine the wake eddy and flow over the submarine ridge over five hours (see later sections). $T$ and $S$ were obtained with a Teledyne Oceanscience underway CTD (UCTD), which consists of Sea-Bird C and $T$ sensors in a compact, weighted probe attached by a Spectra line to a high-speed winch (Rudnick and Klinke, 2007). During this fieldwork, the probe was deployed every $\sim 150 \mathrm{~s}$ from the vessel as it drifted ahead slowly. The probe fell at $3 \mathrm{~m} \mathrm{~s}^{-1}$ to $150 \mathrm{~m}$ and crossed the subsurface $S$ maximum, which traces the flow downstream (see later section on Wake Eddies Farther Downstream). As the probe was recovered, the vessel transited about $200 \mathrm{~m}$ to the next station at speeds $<2.5 \mathrm{~m} \mathrm{~s}^{-1}$. Because the probe's free fall speed was uniform $( \pm 15 \%)$ under these operating conditions, line was not wound on the tailspool. Data are quality-controlled for $S$ spiking using standard methods (Rudnick and Luyten, 1996). These data are then used to calculate in situ and potential density, $\rho$ and $\sigma_{\theta}$. The mean density $\left(\rho_{o}\right)$ is used in some calculations below, while $\sigma_{\theta}$ is contoured in figures. UCTD and ADCP data are objectively mapped on depth surfaces with a Gaussian decorrelation scale of $0.008^{\circ}$ and noise-to-signal ratio of 0.1 (Rudnick and Luyten, 1996). The maps are used to calculate lateral gradients and are plotted where the mean square error map is $<0.25$. Reducing the decorrelation scale by a factor of 2 does not alter any conclusions but reduces smoothing of the results. Further reduction of the decorrelation scale is limited by the resolution of the data.

Survey D examined the mesoscale wake and the downstream propagation of the submesoscale eddies in the mean flow. This survey used SeaSoar to cover a wider area and took place earlier (October 13-18, 2015). SeaSoar, an undulating platform equipped with a Sea-Bird CTD, was towed behind R/V Roger Revelle at $4 \mathrm{~m} \mathrm{~s}^{-1}$ to profile to $400 \mathrm{~m}$ every nine minutes with along-track spatial resolution of $2.8 \mathrm{~km}$. $T$ and velocity data are objectively mapped at $0.1^{\circ}$ and $0.25^{\circ}$.

\section{Modeling System}

Beyond the $1 \mathrm{~km}$ scale surveys $\mathrm{A}-\mathrm{C}$, the incident flow is described by HF radar and a modeling system, while the downstream effects are noted in the model and survey D. We employed the MIT MSEAS (Multidisciplinary Simulation, Estimation, and Assimilation System) modeling system (Haley and Lermusiaux, 2010; Leslie et al., 2010), configured with implicit two-way nested computational domains, in order to have higher accuracy for regional multi-dynamics interactions. 
Such interactions occur around steep topography and include circulations with non-hydrostatic and hydrostatic physics (Ueckermann and Lermusiaux, 2012, 2016), or both geostrophic and strongly ageostrophic motions. Our motivation with this approach is to achieve accurate simulations that resolve locally strong gradients over dynamically significant spatial and temporal scales. Thus, high-order numerical schemes and multi-resolution meshes (allowing optimized refinements) are used. For this work, our simulations were made using a $1 / 225^{\circ}$ grid spanning $420 \mathrm{~km} \times 360 \mathrm{~km}$ with 70 optimized terrain-following vertical levels. Initial conditions were downscaled from $1 / 12^{\circ}$ HYCOM analyses (Cummings and Smedstad, 2013) via optimization for our higher resolution coastlines and bathymetry (Haley et al., 2015). Our simulations were forced with $1 / 4^{\circ}$ Global Forecast System atmospheric fluxes from the National Centers for Environmental Prediction and with tides from the high resolution TPXO8-Atlas from Oregon State University (Egbert and Erofeeva, 2002), with adjustments for our higher resolution geometry (Logutov and Lermusiaux, 2008). We applied a quadratic bottom drag. We note that the local observations (see two previous sections) were not assimilated; MSEAS simulations were fully independent of the observed data.

\section{INCIDENT FLOW}

During survey C on December 9, the HF radar shows westward flow associated with the NEC's encounter with Palau, and flows around the north and south points of Palau (green squares in Figure 1a). At about $7^{\circ} 15^{\prime} \mathrm{N}$, the incident westward flow is topographically blocked at the east coast and is thus at a minimum, while at the south point of Peleliu, the incident flow intensifies upstream and is mainly westward at $0.3 \mathrm{~m} \mathrm{~s}^{-1}$ (Figure 1a). The flow downstream of Peleliu exceeds $0.5 \mathrm{~m} \mathrm{~s}^{-1}$. This strong westward flow produces wake eddies at the south point of Peleliu, similar to those found at the north point of
Velasco (Johnston et al., 2019, in this issue; MacKinnon et al., 2019; Merrifield et al., 2019, in this issue; Rudnick et al., 2019, in this issue; Siegelman et al., 2019, in this issue; Zeiden et al., 2019). The upstream Ro is cyclonic and has a magnitude of about 1 (Figure 1a), which is comparable to the model (Figure 1b). Ro in the wake exceeds 10 and is generated by drag forces on the NEC flow, as it rounds the south point (Figure 1b; see later sections).

\section{WAKE EDDIES}

\section{Currents and Turbulent Drag at the Separation Point}

Here, we document the process of wake eddy formation, evolution, and partial destruction. We describe the currents and turbulent drag as the flow separates from the south point of Peleliu. The currents near Peleliu are comprised of both mean (which for our purposes is at any period longer than tidal) and oscillatory components, with roughly equal magni- ditions, flow rounds the point smoothly without eddies, but with increasing turbulence, a range of processes are noted from the formation of an individual attached eddy to a train of downstream eddies, known as a vortex street. At the north point, the near-bottom turbulence responded to both mean and oscillatory tidal flow speeds (MacKinnon et al., 2019). We expect the same to be true at the south point. The strength of the turbulent drag can be estimated from in situ turbulence measurements at the flow separation point. During survey A (October 31, 2016), a microstructure section was conducted along the submarine ridge extending southward from Peleliu (Figure 3a), where currents reached $1 \mathrm{~m} \mathrm{~s}^{-1}$ westward (Figure 3e). Typical coastal values of the turbulent dissipation rate $\left(\varepsilon=10^{-8} \mathrm{~W} \mathrm{~kg}^{-1}\right)$ are seen away from the topography (MacKinnon and Gregg, 2003), but $\varepsilon$ is elevated by three to four orders of magnitude from 5-10 $\mathrm{m}$ above the bottom (Figure 3f). tude. Flow variability is indicated with ellipses in Figure 2, which are oriented in the direction of maximum variance with the semi-major axis equal to one standard deviation (Figure 2c,f). The mean over the record is also plotted (gray vectors, Figure 2c), but removed prior to the calculation of the ellipses. The tidal and mean flows are about $0.5 \mathrm{~m} \mathrm{~s}^{-1}$ each and combine to produce a current that varies from $0-1 \mathrm{~m} \mathrm{~s}^{-1}$ westward (Figure $2 \mathrm{~b}$ ).

The strength of the turbulence controls the nature of the wake. With laminar con-
Ocean numerical models often parameterize the topographic bottom drag on currents through a drag coefficient, frequently taken to be $C_{d}=2.5 \times 10^{-3}$. However, in regions of variable bottom composition, from sand to coral, $C_{d}$ may vary considerably (Wijesekera et al., 2014). We can use the bottom-enhanced $\varepsilon$ measurements (Figure 3f) to determine the effective $C_{d}$ (Figure 3c). In particular, a quadratic drag formulation is consistent with the existence of a constant stress, or log-layer, in which current 
speed decreases logarithmically towards the bottom. Turbulent dissipation rate $\varepsilon$ then decreases with increasing height above bottom $(h)$ as

$$
\varepsilon \sim u_{\star}^{3} /(k h),
$$

where $k=0.4$ is von Kármán's constant and $u_{*}$ is a characteristic turbulent or friction velocity, related to the free current speed above the boundary layer $(|U|)$ as $u_{\star}^{2}=C_{d}|U|^{2}$ (Dewey and Crawford, 1988). The $\varepsilon$ profiles ended only when the VMP nose cone hit bottom, at which point the shear probes were $28 \mathrm{~cm}$ above the seafloor (Figure $3 c$ ). All $\varepsilon$ values are similar closest to the bottom but drop off dramatically at $h=2-6 \mathrm{~m}$, where stratification limits penetration of turbulence (Perlin et al., 2005). The measured $\varepsilon$ is consistent with values expected from Equation 1 using a much smaller coefficient, $C_{d}=0.3 \times 10^{-3}$ (gray line, Figure $3 c$ ). This result matches the measurements well, particularly in the bottom 1-2 $\mathrm{m}$, where log-layer theory is expected to apply. In contrast, the more frequently used value of $C_{d}=2.5 \times 10^{-3}$ (magenta line, Figure $3 \mathrm{c}$ ) is inconsistent with the $\varepsilon$ measurements here, which are two orders of magnitude lower than predicted by this $C_{d}$ in the bottom $1 \mathrm{~m}$. Consistent with a low $C_{d}$, visual observations confirm that the seafloor is smooth because it is scoured by the strong currents.

In the present MSEAS model, the $C_{d}$ formulation employed is based on Blumberg and Mellor (1987),

$$
C_{d}=\max \left\{C_{\min },[K / \ln (|H-h| / B)]^{2}\right\},
$$

where $C_{\min }$ is a minimum value, $K$ and $B$ are parameters, $H$ is a reference depth, and $h$ is the local bottom depth. We run simulations with all combinations of $K=0.2$ to $0.8, B=0.01$, and $C_{\text {min }}=0.3 \times 10^{-3}$ to $2.5 \times 10^{-3}$. With these terms the largest value at the sill varied from $0.6 \times 10^{-3}$ to 0.01 . We found that, in all cases, these turbulent bottom drags
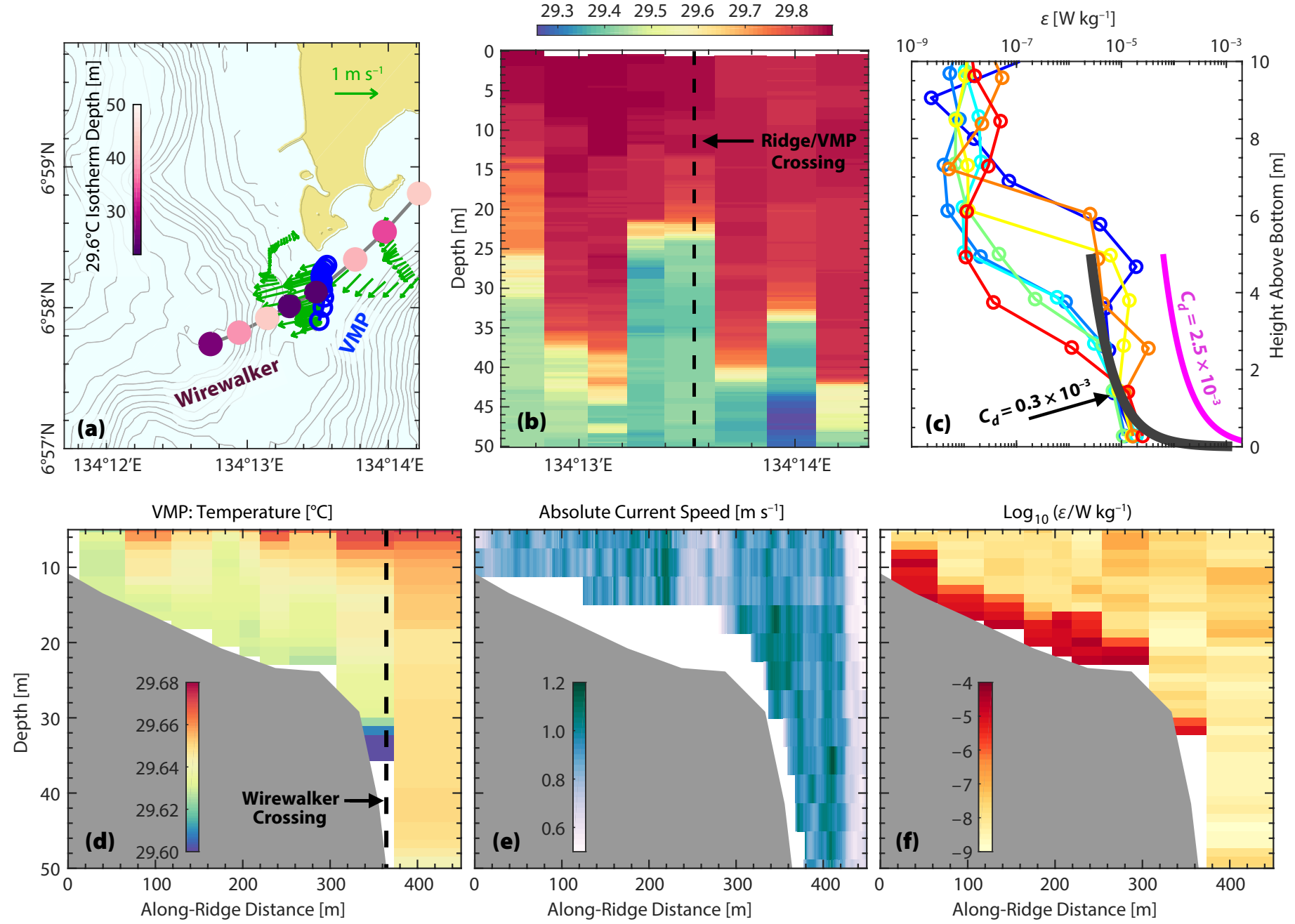



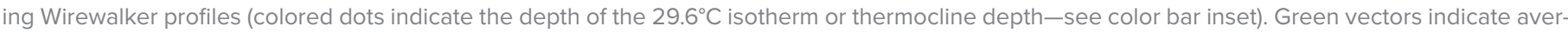

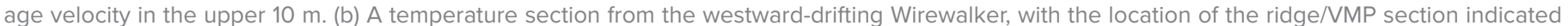

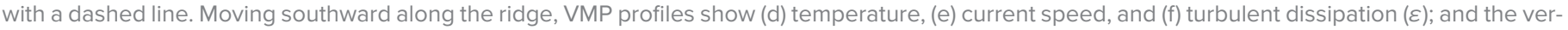

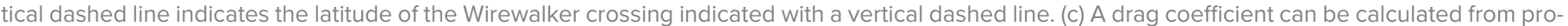

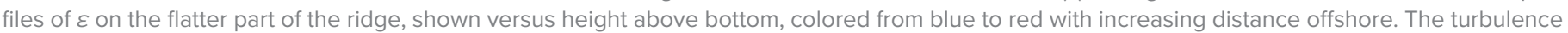
profile expected from a log-layer scaling using drag coefficients of $C_{d}=0.3 \times 10^{-3}$ (dark gray) and $C_{d}=2.5 \times 10^{-3}$ (magenta) are shown for reference. 
were always smaller than the form drag (see later section on Form Drag), which did not vary much with $C_{d}$.

In general, the turbulent drag affects the flow separation and the wake eddy formation. The strength of the turbulence can be expressed via an effective Reynolds number (Signell and Geyer, 1991) or an island wake parameter (Wolanski et al., 1984): $R e_{f}=H /\left(C_{D} L\right)$, where $H=30 \mathrm{~m}$ is the fluid depth and $L=1 \mathrm{~km}$ is a characteristic horizontal scale of the obstacle. For our case, $R e_{f} \sim 100$, which puts this flow firmly in the wake eddy shedding regime. Put another way, flow separation occurs when inertial forces overcome frictional effects, a condition that may be met when the topographic radius of curvature is less than $H / C_{D}$ (Garrett, 1995). With our case, $H / C_{D}=10-100 \mathrm{~km}$ using the observed and typical $C_{D}$ values, which indicates flow separates at most headlands, including the south point of Peleliu, and wake eddies are shed.

\section{Wake Eddy Formation}

Next, we document the formation and initial evolution of small-scale, tidally influenced wake eddies, through both moored time series and vessel-based surveys. The differences in strength and timing of peak flows at the moorings around the island tip provide some insight into wake eddy formation. In particular, we highlight the correspondence between westward flow at site $S$ and southward flow at site $\mathrm{W}$, interpreting the latter as an eddy wake recirculation. These two records fit into a larger context around Peleliu, in which the mean flow equals $\sim 1$ standard deviation of the total current at sites $\mathrm{E}, \mathrm{S}$, and $\mathrm{W}$ over the whole record, while at site $\mathrm{N}$, the mean flow is near zero (as illustrated by the gray mean flow vectors and red current ellipses in Figure 2c). At sites $\mathrm{E}$ and $\mathrm{S}$, the mean current is westward due to the incident flow of the NEC. At site $\mathrm{S}$, the flow intensifies, as it is constrained to flow over and around topography (Figure 2c).

Then, we focus on the time series during surveys $\mathrm{B}$ and $\mathrm{C}$ (left and right columns, Figure 2). Sometimes over the six-month record, the phasing of currents at sites $\mathrm{S}$ and $\mathrm{W}$ closely follows the tidal elevation, but at other times, such as during surveys $B$ and $C$, it seems linked to the time that the wake eddy forms, as follows. At maximum/minimum westward flow at site $S$, southward flow at site $\mathrm{W}$ is near zero/maximum (Figure 2a,b,d,e). A subsampled vector plot illustrates this timing for sites $\mathrm{S}$ and $\mathrm{W}$ (the onshore direction corresponds to increasing time in Figure 2c,f).

Mean flow and tidal flow combine for maximum westward flow at site S, producing an eddy whose flow rotates clockwise into the lee, reaches the coast, and splits, with some waters going southward (northward) past site W (N) (in surveys B and C; Figures $4 \mathrm{a}$ and $5 \mathrm{c}$ ). When combined with a tidal flow, the time needed to recirculate produces a southward (zero mean) current at site $\mathrm{W}(\mathrm{N})$ at a three- to six-hour lag from the peak westward flow at site $\mathrm{S}$ (Figure $2 \mathrm{c}, \mathrm{f}$ ). The timescale for the recirculation (or, in other words, the time for maximum flow at site $S$ to rotate, reach the coast near site $\mathrm{W}$, and produce maximum southward flow there) is six hours, in reasonable agreement with the fluctuations of $u$ at site $\mathrm{S}$ (Figure $2 \mathrm{~b}, \mathrm{e}$ ). This periodicity either reinforces or reduces semidiurnal tidal flow, depending on the phasing of the tide.

The time evolution of eddy development may reflect a combination of frequencies of the incident flow (i.e., tidal) and the intrinsic dynamical timescales at which eddies are shed even with a steady incident flow. This phenomenon, referred to as a vortex street, is expected under the conditions here $\left(R e_{f} \sim 100\right.$; Chang et al., 2013). An attached wake eddy grows until it is large enough to influence flow and pressure gradients at the separation point, then the eddy detaches, and the process begins anew (Kundu and Cohen, 2002). For idealized flow around obstacles, the intrinsic eddy shedding timescale is linked to the Strouhal number: $S t=L /(T U)$, where $U$ is the characteristic incident flow mag- nitude, $L$ is a characteristic lateral length scale of the obstacle, and $T$ is the eddy shedding period. Empirically, many studies find St 0.2 (Davies et al., 1989; Dong et al., 2007; Magaldi et al., 2008). For the measurements described here, reasonable choices of $L=2 \mathrm{~km}$ and $U=0.5 \mathrm{~m} \mathrm{~s}^{-1}$ suggest an intrinsic eddy shedding timescale of six hours. The similarity between this timescale at the south point and the duration of westward flow from a semidiurnal tide and mean flows may effectively generate eddies.

The observed wake eddies are small and intense. A rough scaling based on the velocity difference of $1 \mathrm{~m} \mathrm{~s}^{-1}$ across a $2 \mathrm{~km}$ diameter yields a Ro $\sim 30$. By making similar calculations between currents measured by ADCP moorings at sites $\mathrm{S}$ and $\mathrm{W}$, we produce a time series of Ro with values reaching 80 and 65 (Figure $2 b, e$ ). These calculations are supported by surveys $B$ and $C$, which identify an anticyclonic, $2 \mathrm{~km}$ diameter eddy in the lee of Peleliu. The spatial structure of the wake eddy in surveys $\mathrm{B}$ and $\mathrm{C}$ is described further in the next section, which confirms the velocity difference across the eddy exceeds $1 \mathrm{~m} \mathrm{~s}^{-1}$ and the large Ro inferred from the moored time series. Due to the low latitude (small $f$ ), the eddies have large Ro, but even at mid-latitudes (larger $f$ ), these velocity gradients would produce Ro $\sim 10$.

\section{Initial Consequences:}

\section{Wake Eddy Fronts}

In addition to the elevated turbulence where flow directly drags on the bottom, instabilities due to current shear or other processes within the wake eddies enhance mixing downstream. During survey B (November 5, 2016), the westward flow rounds the south point, heads offshore, and produces an eddy, which then recirculates over 1-2 km in the lee of the point (velocity vectors in Figure 4a; similar eddies in the moored time series in Figure 2 and during survey $\mathrm{C}$ in Figure 5c). A section through the eddy reveals a sloping front associated with converging water masses (Figure $4 b, f)$. 
Turbulent dissipation rate $\varepsilon$ is elevated along the sloping front (Figure 4d) and is orders of magnitude higher than typical coastal levels of $10^{-8} \mathrm{~W} \mathrm{~kg}^{-1}$ (similar to values away from topography in survey A in Figure 3f; MacKinnon and Gregg, 2003). Velocity through the wake eddy is vertically sheared in magnitude and direction (Figure $4 \mathrm{e}$, but $v$ not shown). Shear instabilities contribute to the elevated $\varepsilon$ on the cooler side of this front $\left(134^{\circ} 12.3^{\prime}-12.7^{\prime} \mathrm{W}\right.$, Figure $\left.4 \mathrm{~d}, \mathrm{e}\right)$.

Considerable $T-S$ changes within this section suggest different water mass histories. As two water masses come into close contact, stirring of $T-S$ structures along isopycnals (i.e., "spice") acts as a tracer in the absence of mixing (longitude in color, Figure 4b). The eastern and western water masses appear identical, suggesting that this water recirculates with the eddy. However, in the middle, we see a distinct water mass, which may be a remnant of southward flow from earlier in the tidal cycle, entrained by the eddy recirculation. At one edge of this cooler water mass, very sharp fronts are visible in $T\left(0.3^{\circ} \mathrm{C}\right.$ changes over 1-10 m laterally, Figure 4c). At the western edge, we see evidence of interleaving, possibly from submesoscale instabilities, while at the eastern edge, the front is still sharp but on scales of order $10 \mathrm{~m}$. Fronts like this are often visible at the surface with clear changes in surface roughness or whitecapping, and they were used to guide the survey pattern.

\section{Wake Eddies Farther Downstream}

The combined tidal and steady westward flow produces eddies at the north and south points of Palau, but differences are noted in the eddies farther downstream. When the tidal current is eastward and the total flow approaches zero, the eddy detaches from the point. As the total current becomes westward again, the eddy then propagates downstream. Thus, a sequence of submesoscale tidal eddies is found downstream (MacKinnon et al., 2019). Modeled surface Ro shows that a sequence of cyclonic/ anticyclonic eddies is formed at the north/ south point, is advected westward with the NEC, and circulates around larger, island-scale wake eddies (Johnston et al., 2019, in this issue). Similar model results during survey $\mathrm{C}$ are found at the south point (Figure 1b). Upstream, the magnitude of Ro is $<1$ from both the model and $\mathrm{HF}$ radar (Figure 1). At the points, the magnitude of Ro exceeds 15, comparable to our observations (Figures 4a and 5c). Farther downstream, Ro is about 10 in submesoscale eddies, and a $60 \mathrm{~km}$ diameter (or island-scale) eddy is noted (Figure 1b).

Some asymmetry is noted in the model simulations between the anticyclonic eddies in the north and the cyclonic eddies in the south. In the north, distinct cyclonic submesoscale eddies are located along the periphery of a cyclonic, islandscale eddy. In the south, an anticyclonic island-scale wake eddy is found, but distinct anticyclonic eddies are fewer. The northern, cyclonic eddies are more distinct, which suggests they are more stable than anticyclonic eddies. Large horizontal shears and negative vorticity arise
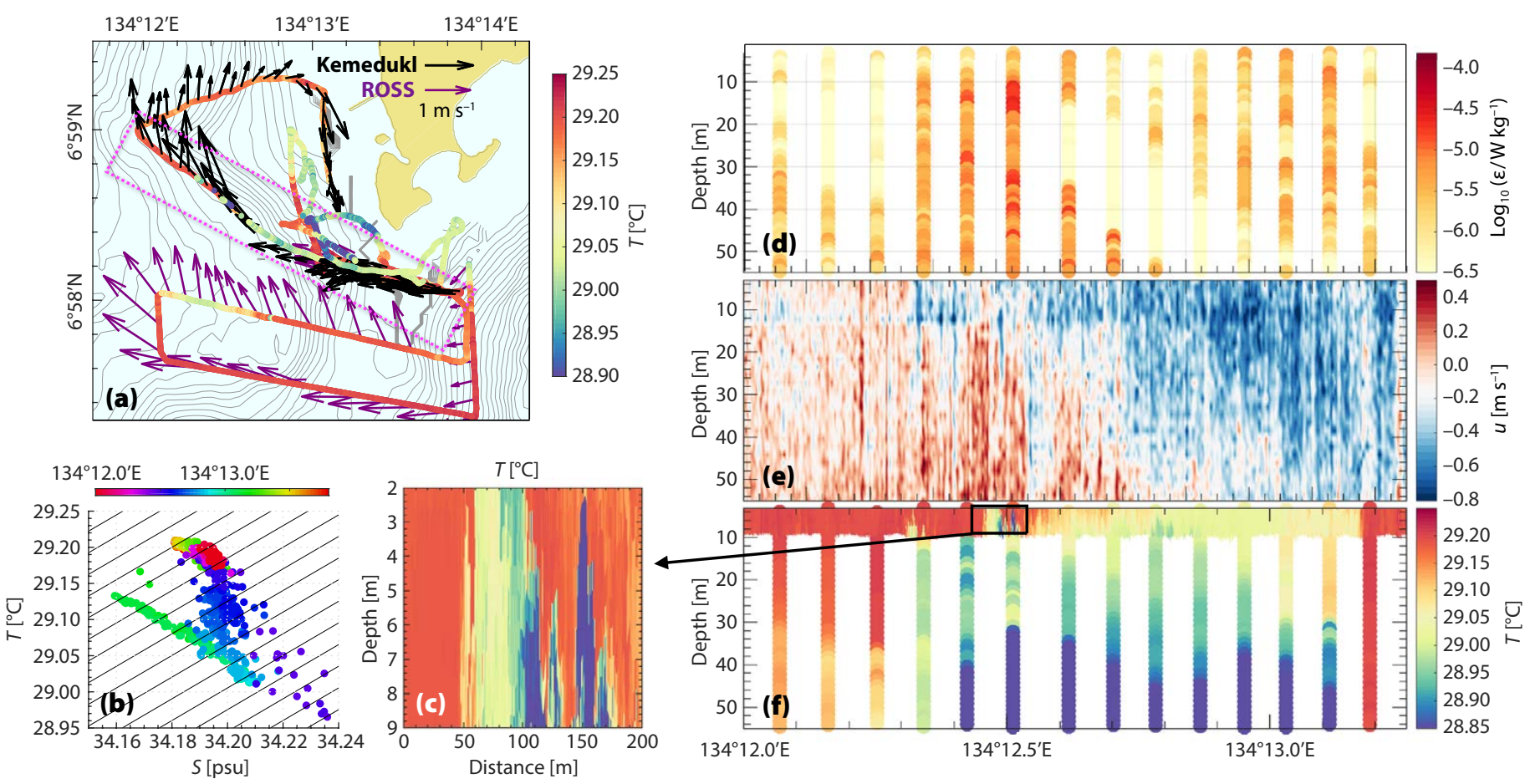

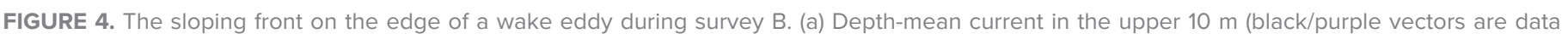





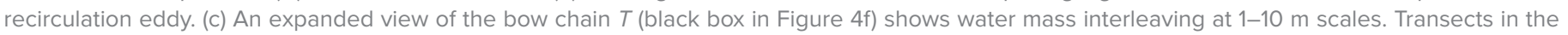
dotted magenta box in panel (a) are plotted for (d) VMP profiles, (e) $u$, and (f) $T$ (bow chain data in the upper 10 m, VMP profiles below). 
near the coast due to friction but cannot be sustained once the flow detaches from the south point (D'Asaro, 1988; Gula et al., 2016). Centrifugal instability occurs for Ro $<-1$. These model results strongly resemble an idealized simulation of steady westward flow around an island, which displays (a) submesoscale cyclonic eddies wrapping around an island-scale cyclonic eddy at the north point, and (b) anticyclonic vorticity generation at the south point but without a submesoscale eddy train (Musgrave and Peacock, 2016). Without tides, anticyclonic vor- ticity is generated in streaks at the south point in a model because of the instability right at the point of flow separation, while with tides a periodicity is seen in the south point's wake because the total flow changes from a westward maximum to zero with the tides.

Survey D shows anticyclonic wake eddies propagating downstream from the south point. However, the SeaSoar data barely resolve these features because the along-track resolution is $<3 \mathrm{~km}$, while the cross-track resolution is about $5 \mathrm{~km}$ (in Figure $6 c$, the gray line traces the cruise track, and small dots indicate individual profiles). Nevertheless, the effect of the eddies is apparent in $T$ variations on isopycnals (i.e., spice; Figure 6b). Density is dynamically active, while spice is passive and acts as a tracer in the absence of mixing. Also, by examining this variability on isopycnals, the effects of internal wave heaving are removed. Three isopycnals are considered $\left(\sigma_{\theta}=24.92,25.82\right.$, and $25.98 \mathrm{~kg} \mathrm{~m}^{-3}$ ), which have mean depths of 90,125 , and $135 \mathrm{~m}$, respectively. The observed warm, submesoscale eddies moving in a westward current stand out


FIGURE 5. Objective maps from survey C (December 9, 2016) at $77 \mathrm{~m}$ show the spatial structure of the lee wave in (a) salinity (S) and (b) vertical velocity $(w)$. The small gray dots in (a) indicate locations of the underway CTD profiles. The density difference from the mean $\left(\sigma_{\theta}=23.12 \mathrm{~kg} \mathrm{~m}{ }^{-3}\right)$ is contoured with negative/positive values in gray/black at intervals of $0.15 \mathrm{~kg} \mathrm{~m}^{-3}$, with the thick black contour at $0 \mathrm{~kg} \mathrm{~m}^{-3}$. Mooring sites W, S, and $\mathrm{E}$ are labeled. The wake eddy is best seen in (c) Ro and current. Current vectors are plotted with a scale vector of $0.5 \mathrm{~m} \mathrm{~s}^{-1}$ eastward. Isobaths are contoured in brown at $200,400,600$, and $800 \mathrm{~m}$. Maps along $6^{\circ} 57.5^{\prime} \mathrm{N}$ show the vertical structure of the lee wave in (d) $S$, (e) $w$, and (f) $\nabla \cdot u / f$. In panel (d), temperature is contoured from $\theta=15-29^{\circ} \mathrm{C}$ at intervals of $2^{\circ} \mathrm{C}$. In panel (e), density is contoured from $\sigma_{\theta}=21.5-25.5 \mathrm{~kg} \mathrm{~m}^{-3}$ at intervals of $0.5 \mathrm{~kg} \mathrm{~m}^{-3}$. In panel (f), current vectors indicate horizontal flow; the scale vectors indicate $u / v=0.5 \mathrm{~m} \mathrm{~s}^{-1}$ eastward/northward (towards the right/top) with the depth profile of the submarine ridge in the lower portion. Underway CTD profile locations are indicated by black lines on the top axis of panel (d). 
at $120 \mathrm{~m}$ (Figure $6 \mathrm{~b}$ ) because they lie at a vertical and lateral interface of spice: on shallower/deeper isopycnals, warmer $T$ is in the south/north (Figure 6a,c). The eddies were transported $50 \mathrm{~km}$ downstream by the westward NEC and possibly recirculate in the island-scale wake eddy with a diameter of about $50 \mathrm{~km}$ (Figures 1b,c and 6b). Eddies are released from the point every 12 hours as the semidiurnal tide opposes the westward mean flow, resulting in a separation of $10 \mathrm{~km}$ in a $0.25 \mathrm{~m} \mathrm{~s}^{-1}$ mean flow. Because each meridional section took about six hours to complete, the measured downstream distance between distinct eddies increases and should be about $15 \mathrm{~km}$, consistent with the observed spacing.

\section{LEE WAVES}

As noted in the introduction, flow encountering abrupt topography produces wake eddies and internal lee waves. The two responses exist simultaneously, with both extracting energy and momentum from the incident flow through different physical mechanisms. Here, we investigate the internal lee wave response. An initial suggestion of lee wave formation is visible: as the Wirewalker drifts over the ridge, vertical thermocline excursions of
20-25 $\mathrm{m}$ are equal to about half the water depth (Figure 3b). These vertical excursions lift cooler water upward, which is also noted in the along-ridge VMP section right over the ridge (in $35 \mathrm{~m}$ water depth; Figure 3d), where it intersects the Wirewalker track (Figure 3a).

Similar isopycnal displacements occur when stratified flow is forced over deeper portions of this submarine ridge, forming internal lee waves that were evident during survey C (December 9, 2016; Figure 5). At this time, the incident flow is strong enough that when it reaches the submarine ridge (isobaths in Figure $5 c$ and depth profile across the ridge in lower part of Figure 5f), the flow can move water vertically and overcome the stratification (represented by the buoyancy frequency, $N$ ). This occurs as the Froude number approaches 1: $\mathrm{Fr}=U / N H \sim 0.5$, where typical scales are $U=0.5 \mathrm{~m} \mathrm{~s}^{-1}$ for the current, $N=0.01 \mathrm{~s}^{-1}$, and $H=100 \mathrm{~m}$ for the vertical extent of topographic blocking of the flow (Figures 5 and 8b,c). The peak-to-peak vertical displacement of isotherms and isopycnals exceeds $30 \mathrm{~m}$ (Figure 5d,e), as is also confirmed by the independent MSEAS simulations (Figure 7). The isopycnal crests tilt upstream (Figure 5d), which indicates they are propagating into the flow and that the flow arrests the wave propagation, if both have the same magnitude. The longest waves (denoted as mode-1) have a wave speed of $c=N H \sim 1 \mathrm{~m} \mathrm{~s}^{-1}$, but waves with smaller wavelengths (mode- 2 or higher) will be slower and could match the flow speed. The subsurface $S$ maximum serves as a passive tracer of these motions (Figure 5d); its downstream patterns were noted earlier (Figure 6). The low pressure (downward isopycnal displacements and low $S$ at $77 \mathrm{~m}$; Figure 5a,d) associated with the lee wave is not at exactly the same location as the wake eddy identified in Ro (Figure 5c).

As the incident flow passes the upstream/downstream flank of the submarine ridge, flow accelerates/decelerates and diverges/converges (Figure 5f). The horizontal divergence is scaled by $\mathrm{f}$ and $\nabla \cdot \bar{u} / f$ exceeds 35 , where $\bar{u}$ is the velocity vector. By integrating the continuity equation $\left(\nabla \cdot \bar{u}=-\partial_{z} w\right)$ over depth, we estimate the vertical velocity, $w$, which reaches $2 \mathrm{~cm} \mathrm{~s}^{-1}$ (Figure 5e). This value exceeds typical $w$ at mid-latitude fronts, which is on the order of $10 \mathrm{~m} \mathrm{day}^{-1}$. Examining the $u$ time series at site $\mathrm{S}$, the peak flow occurs over six hours (gray bar
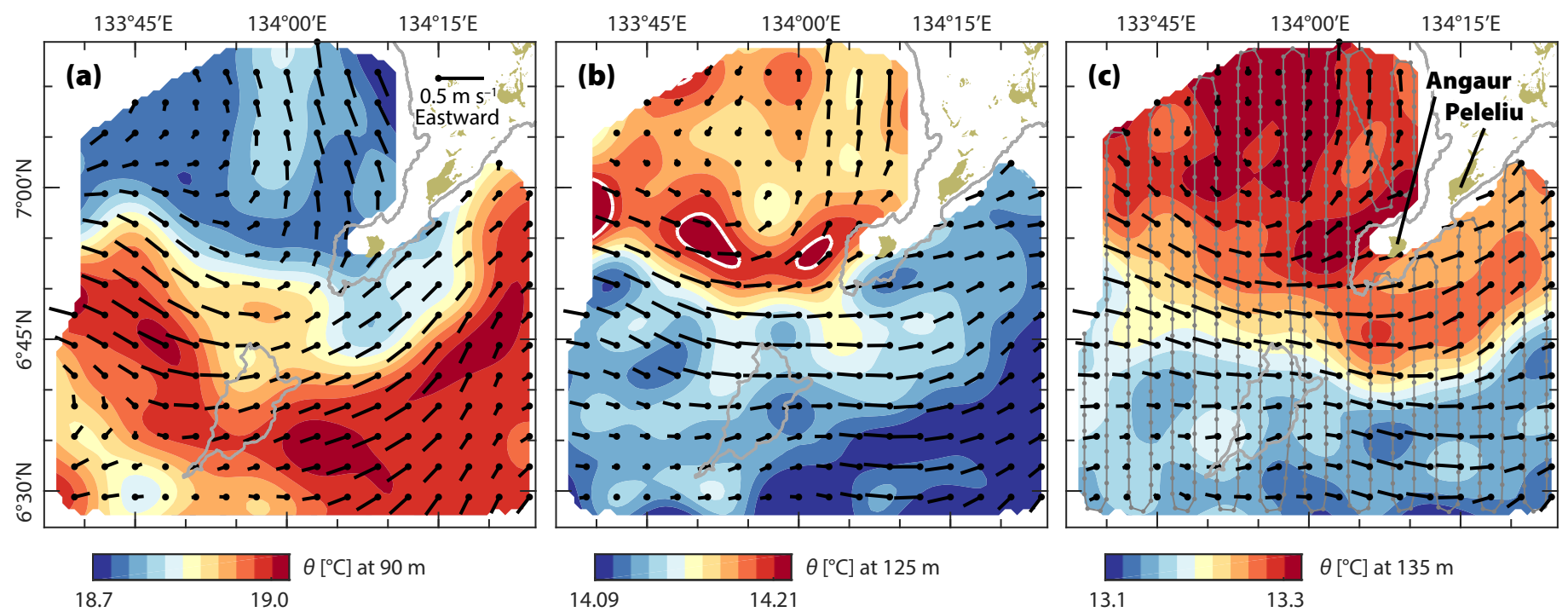

FIGURE 6. The tracer spice ( $\theta$ on isopycnals) is plotted on three isopycnals: (a) $24.92 \mathrm{~kg} \mathrm{~m}^{-3}$ at a mean depth of $90 \mathrm{~m}$, (b) $25.82 \mathrm{~kg} \mathrm{~m} \mathrm{~m}^{-3}$ at a mean depth of $125 \mathrm{~m}$, and (c) $25.98 \mathrm{~kg} \mathrm{~m}^{-3}$ at a mean depth of $135 \mathrm{~m}$. Wake eddies are visible in spice (white outlines highlight these spice contours), and in panel (b) downstream of Peleliu and Angaur because this isopycnal is at a lateral and vertical interface between shallower/deeper isopycnals, which have warmer $T$ in the south/north (panels a and c). The $800 \mathrm{~m}$ isobath is contoured. Cruise track and profiles (gray line and dots, panel c) and scale vector of $0.5 \mathrm{~m} \mathrm{~s}^{-1}$ eastward are shown (panel a). 
in Figure 2e). To estimate vertical displacements, one approach is to integrate a typical $w$ of $1 \mathrm{~cm} \mathrm{~s}^{-1}$ over six hours, which then exceeds $200 \mathrm{~m}$ and is much larger than the observed isopycnal displacements of $30 \mathrm{~m}$. With the best resolution along the one zonal line, we likely overestimate $\partial_{y} v$ and thus $w$. To test this method, some calculations in this section involving $w$ are repeated further below, but with w obtained only from $\partial_{x} u$, which reduces some values by a factor of two.

Our second approach examines temporal variability of vertical displacements in the model results. The root mean square (RMS) of $w$ averaged over one day has peak values of about $1 \mathrm{~cm} \mathrm{~s}^{-1}$. The regions exhibiting these velocities are narrow $(\sim 1.8 \mathrm{~km})$, tied to the topography, and of opposite sign on either side of the ridge. The RMS horizontal velocity of the simulation is $0.15 \mathrm{~m} \mathrm{~s}^{-1}$, and so a fluid parcel only remains in the region of high $w$ for 3.3 hours. In the case of a fluid parcel starting at the edge of the high upward $w$, it would spend 3.3 hours in upward flow and 2.7 hours in downward flow for a net displacement of about $40 \mathrm{~m}$. The $w$ estimated from the data have even shorter length scales, so the parcels spend even less time in either upward or downward velocities.

The regions of upward and downward velocity are confirmed by the independent measurement of isopycnal displacements; the $w$ estimate is derived entirely from the ADCP, while the isopycnal displacements are obtained by the UCTD. Isopycnals move upward where $w$ is positive (Figure 5e). The wavelength is about $2 \mathrm{~km}$, which is similar to the width of the ridge at $400 \mathrm{~m}$. Further confirmation comes from $S$ and $w$ on depth surfaces, where the orientation of $S$ and $w$ crests is parallel to isobaths (running roughly from northeast to southwest; Figure 5a,b). The model simulated $S$ also traces the incident flow, which is smooth upstream, but as it passes the submarine ridge, vertical displacements of up to $30 \mathrm{~m}$ with horizontal length scales of 1-2 $\mathrm{km}$ are noted (Figure 7 ). These verti- cal excursions correspond to $T$ changes of $1^{\circ} \mathrm{C}$ at $40 \mathrm{~m}$ depth and $4^{\circ} \mathrm{C}$ at $130 \mathrm{~m}$ depth over distances of $1 \mathrm{~km}$ (gray contours, Figure $5 \mathrm{~d}$ ). The $T$ changes in the upper $40 \mathrm{~m}$ are comparable to those recorded by the Wirewalker closer to the point during survey A (Figure 3b).

As the flow passes over the topography, it loses energy due to the generation of lee waves. The energy deposited into the waves arises as water is forced over the ridge and then oscillates in its lee. This vertical energy flux is $p^{\prime} w$, where $p^{\prime}$ is the baroclinic pressure perturbation. Because we do not have full-depth measurements, we neglect the depth-mean contribution to $p^{\prime}$ and assume the main contribution is from the baroclinic waves, which seems reasonable because the isopycnals are tilted into the flow (Figure 8a). Because the waves are arrested by the mean flow, they may dissipate close to their generation site. If the energy flux is constant, then energy is transported away from the source. However, the observed energy flux convergence with height indi- cates energy is lost above the topography: $\partial_{z}\left(p^{\prime} w\right)=1.6 / 60 \sim 0.03 \mathrm{~W} \mathrm{~m} \mathrm{~m}^{-3}$ or $3 \times 10^{-5} \mathrm{~W} \mathrm{~kg}^{-1}$, which coincides with the largest measured turbulent dissipation (Figures 4d and 8d). Using $w$ only obtained from $\partial_{x} u$ has minimal effect (because the gradient is similar) on the estimated dissipation.

\section{FORM DRAG}

The incident flow is affected by three types of form drag: from lee waves, from pressure drops across the submarine ridge, and from pressure drops due to wake eddies. Form drag on the flow exerted by lee waves arises from the correlation of vertical and horizontal wave velocities: $\tau_{f}=\rho_{o} u^{\prime} w$, where $u^{\prime}$ is calculated as the deviation from the mean on each depth level (Figure 8b). This quantity is positive on average over the zonal line, indicating upward transport of eastward momentum by the waves. The convergence of this momentum flux will slow the westward flow. If this drag lasts over six hours (i.e., $\partial_{z} \tau_{f}=\rho_{o} \partial_{t} u$ ), we obtain

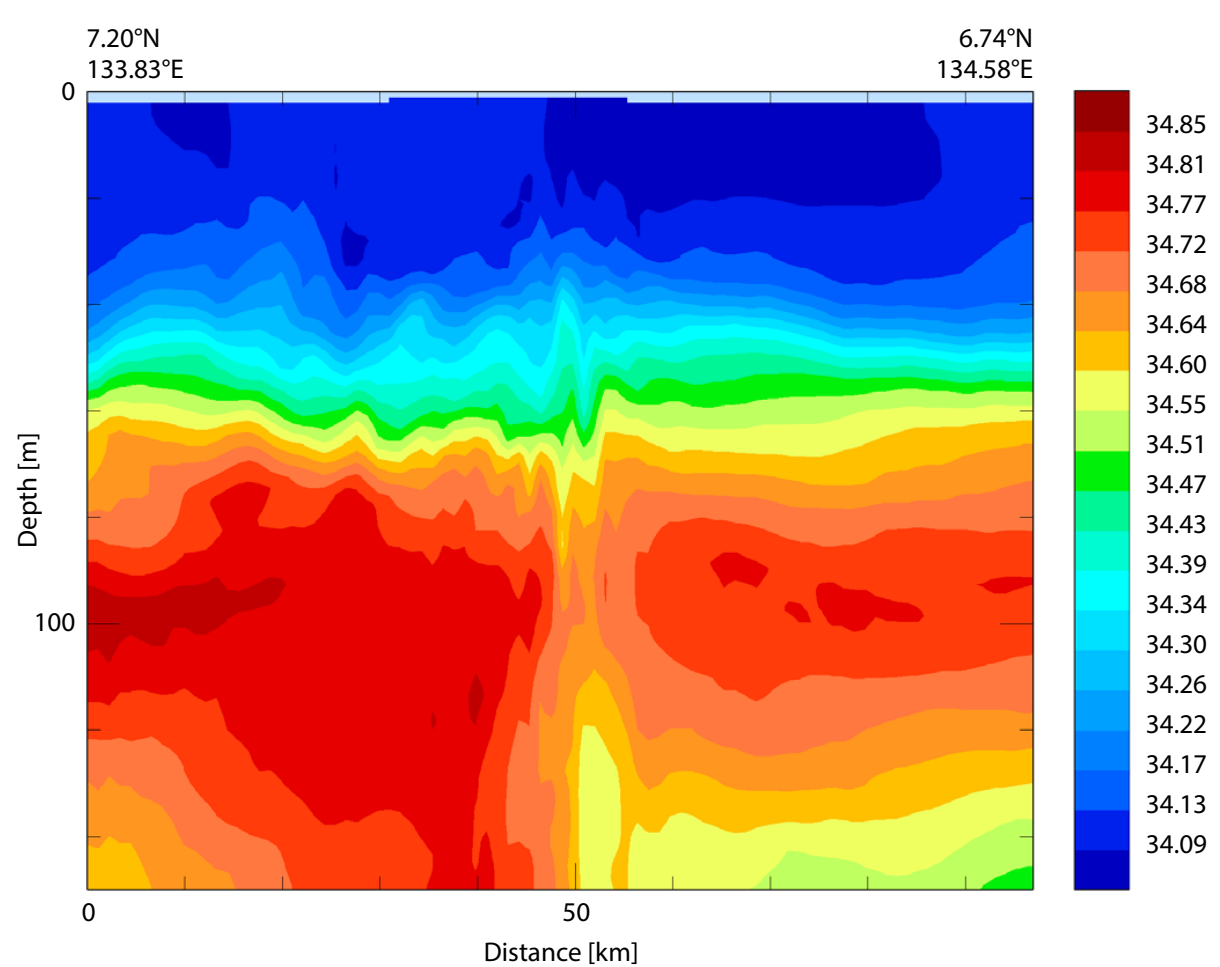

FIGURE 7. The diagonal slice through the channel between Angaur and Peleliu (Figure 1c), as simulated by the MIT-MSEAS modeling system. It shows upstream $S$ aligned along depth surfaces (distances $>50 \mathrm{~km}$ ), with small total $S$ variations such that $S$ acts as a tracer of the flow. The $S$ maximum is constricted over the topography at $50 \mathrm{~km}$ and then displays vertical displacements with scales of $1-2 \mathrm{~km}$ in the horizontal and up to $60 \mathrm{~m}$ peak-to-peak in the vertical in the lee (distances $<50 \mathrm{~km}$ ). 
$\Delta u=0.7 \mathrm{~m} \mathrm{~s}^{-1}$. Using $w$ only obtained from $\partial_{x} u$ reduces $\Delta u$ to $0.2 \mathrm{~m} \mathrm{~s}^{-1}$, which is still about half the mean westward current. The wave drag would produce considerable deceleration of the mean flow, if it were not accelerated by other terms in the momentum equation. The mean lee wave drag is $<1 \mathrm{~Pa}$ (Figure $8 \mathrm{~d}$ ), but our measurements do not extend over the whole water column. Nevertheless, these values are much greater than the bottom
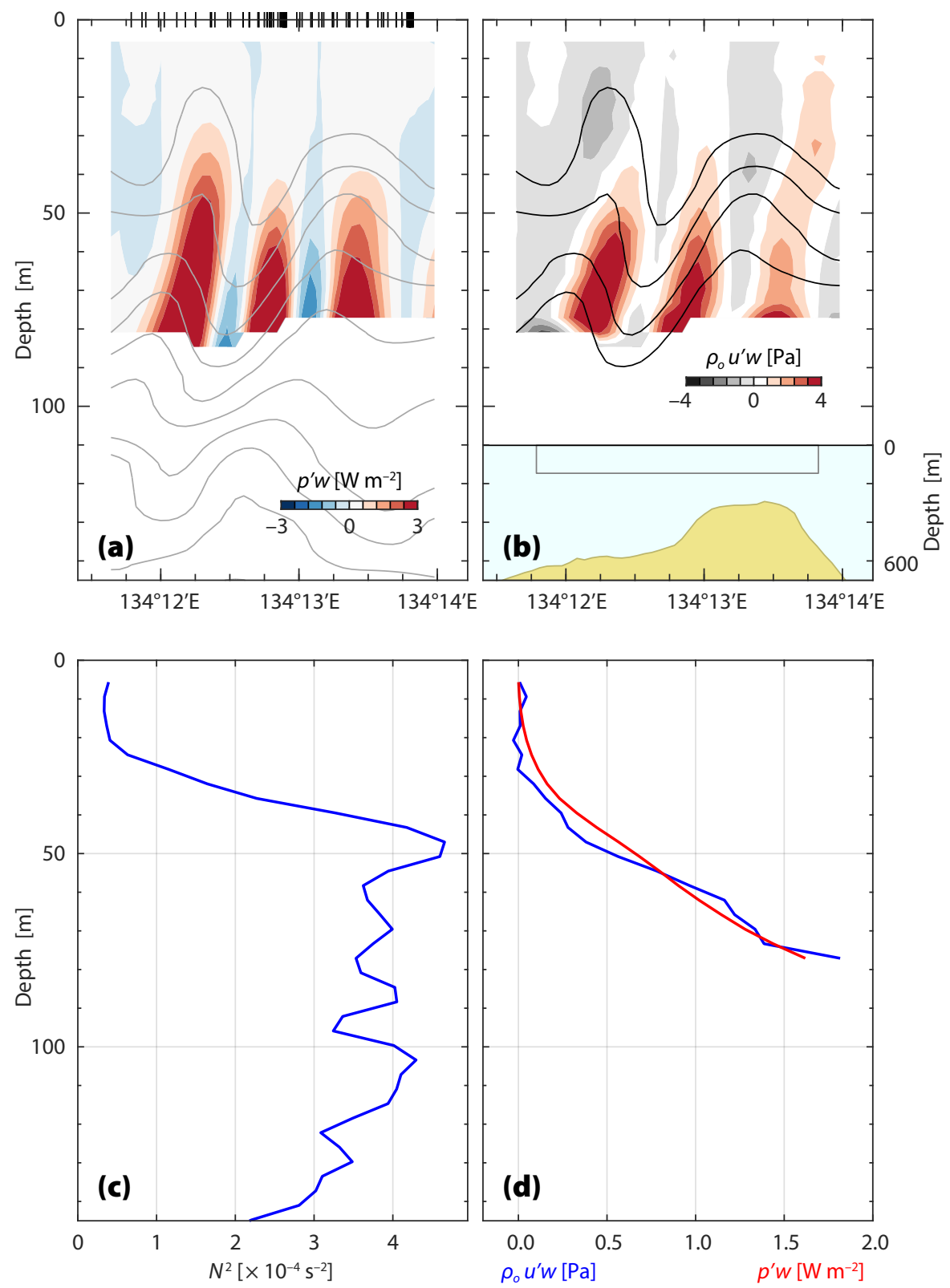

FIGURE 8. Objective maps from survey C (December 9, 2016) along 657.5' $\mathrm{N}$ show the vertical structure of the lee wave in (a) $p^{\prime} w$ and (b) $\rho u^{\prime} w$, where $p^{\prime}$ is the baroclinic pressure perturbation, $w$ is the vertical velocity, $\rho$ is density, and $u^{\prime}$ is wave velocity. Density is contoured from $\sigma_{\theta}=21.5-25.5 \mathrm{~kg} \mathrm{~m}^{-3}$ at intervals of $0.5 \mathrm{~kg} \mathrm{~m}^{-3}$. The depth profile of the submarine ridge is indicated in the lower portion of panel (b). Underway CTD profile locations are indicated by black lines on the top axis of panel (a). Mean profiles along $6^{\circ} 57.5^{\prime} \mathrm{N}$ of (c) $N^{2}$, and (d) $p^{\prime} w$ and $\rho u^{\prime} w$. values of about $0.1 \mathrm{~W} \mathrm{~m}^{-2}$ in Trossman et al. (2016) and dividing by a typical bottom velocity of $0.1 \mathrm{~m} \mathrm{~s}^{-1}$ yields a wave stress of $1 \mathrm{~Pa}$ ). In HYCOM simulations, this parameterized form drag impacts the overall energy budget, deep stratification, deep velocities, vertical structure of mesoscale flow, and, to a lesser extent, sea surface height and velocity variance (Trossman et al., 2016; Arbic et al., 2019, in this issue). On the other hand, a different regional simulation used to conduct an experiment with and without topography around Palau yielded minimal differences in the downstream flow (Gopalakrishnan and Cornuelle, 2019, in this issue). The difference in form stress averaged across $5^{\circ}-10^{\circ} \mathrm{N}$ is only about $0.1 \mathrm{~Pa}$ or $10 \%$. A closer examination of the downstream effects is warranted.

Form drag often exceeds bottom drag. For comparison, typical coastal bottom drag values are about $0.1 \mathrm{~Pa}$ over a flat seafloor, while a small bank interrupting alongshore flow creates form drag $>1 \mathrm{~Pa}$ due to the pressure drop across its length (Moum and Nash, 2000, and references therein). The submarine ridge south of Peleliu has an area of about $2 \mathrm{~km}^{2}$, which we assume produces a mean form drag of about $1 \mathrm{~Pa}$ (see section on Lee Waves). Over this topography, a total force of $2 \mathrm{MN}$ from form drag is felt by the flow. With similar size topography adjacent to the north and south sides of both Velasco and Angaur, there are potentially five areas with similar form drag around Palau. The bottom drag is estimated as follows: we use $\tau_{b}$ from the south point, which is likely an overestimate due to smaller $U$ along the east coast, but on the other hand, $C_{d}$ may be a more typical value elsewhere; bottom slopes around Palau are steep and therefore we generously assume a shelf width of $200 \mathrm{~m}$, and we use an alongshore distance of $100 \mathrm{~km}$. This yields a total force of about $2 \mathrm{MN}$ from bottom drag. Thus, one submarine ridge may exert as much form drag on the incident flow as the entire coastline of Palau via bottom drag.

Because the survey $\mathrm{C}$ observations did not extend to the bottom, we turn to 
the model for form drag values. Over the submarine ridge, form drag arises as flow encounters a pressure drop across the ridge; this was computed from MSEAS simulations first by integrating bottom pressure times topographic slope along two sections (one at $6^{\circ} 57.5^{\prime} \mathrm{N}$ and the other shifted $1 \mathrm{~km}$ to the north) between the $500 \mathrm{~m}$ isobaths on either side of the ridge. The $500 \mathrm{~m}$ limit is below the $450 \mathrm{~m}$ depth, at which water flows over the ridge. The total drag force is then the mean value from the two sections multiplied by their separation distance. We found that this force was correlated with both the tidal flow and the wind-driven variability of flow during the simulation. Initially, the daily winds were weak and northeastward (opposed to the ocean current), leading to a mean westward flow south of Peleliu averaging about $0.2 \mathrm{~m} \mathrm{~s}^{-1}$ at $70 \mathrm{~m}$ depth. The winds turned westward one day before and southwestward on the day of survey C (December 9). The wind strength increased for four days. As a result, the current reached about $0.5 \mathrm{~m} \mathrm{~s}^{-1}$ at $70 \mathrm{~m}$ depth. During the initial period with weaker winds, the RMS total form drag force exerted by the ridge was simulated at $14 \mathrm{MN}$, while during the period of stronger winds this RMS total force was $29 \mathrm{MN}$. Averaged over the entire period, the simulated RMS was $21 \mathrm{MN}$. The form drag at the ridge was also directly computed by integrating over the bottom surface area (McCabe et al., 2006). This led to similar values of $10-30 \mathrm{MN}$.

The form drag from the submesoscale tidally influenced wake eddies was calculated in a similar manner, again using either line integrals or the more formal area integral but here only in the vertical region where the eddies have strong support. For the former, the simulated pressure was integrated across the eddy to the east side of the topography encountered by the incident flow. The endpoints were chosen to be either the deepest value common to both sides or the maximum depth of the considered eddy. The cross-track length was estimated from the dimensions of the eddy. The resulting total drags ranged from 8-24 MN with an RMS of $18 \mathrm{MN}$. If instead we compute the area integral in the vertical region where eddies have strong support, we find values from $10 \mathrm{MN}$ to $80 \mathrm{MN}$, depending on the size of the eddy. These values were not correlated with the wind but varied with the eddy's size (diameters from 1.5 to $3.4 \mathrm{~km}$ ), depth, and velocity. In summary, wake eddies produce a form drag comparable to that from pressure drops across the submarine ridge. These form drags exceed the wave and bottom drags.

\section{LOCAL IMPORTANCE}

Three examples illustrate that the local effect of these topographic flows is considerable. First, the combination of currents from the NEC, wake eddies, tides, fronts, and lee waves, which is hazardous to divers, is not always simply linked with tidal elevation. The area, known as the Peleliu Express, is a popular tourist dive site due to the numbers of large fishes attracted by the high current conditions. However, the combination of strong currents, sudden changes in direction, and the lack of predictability has made it a treacherous location for diving. In many cases, when boats have lost track of their divers or had breakdowns while divers were in the water, groups of divers have been swept away far offshore, with some never located, resulting in fatalities.

Second, these tidal wake eddies are often associated with areas used by large fishes as transient spawning aggregations. The currents may initially serve to disperse eggs or reduce levels of predation from benthic planktivores, but they also play a role in retaining eggs and larvae near the reef areas as they circulate around the submesoscale eddy and possibly the larger island-scale eddy. Several species of large fishes use the south point of Peleliu for spawning aggregations, principally around the times of full and new moons when tides are maximal (Sadovy de Mitcheson and Colin, 2012), but why fish select this specific site remains a matter of conjecture, with potentially intersecting reasons. Previous modeling work shows spawning sites at headlands with strong (i.e., greater Ro) and predictable wakes, which concentrate the eggs and keep them close to shore (Karnauskas et al., 2011). We speculate that the wake at Peleliu may maintain a similar balance between an initial, rapid dispersal of eggs to avoid predators and retention of the eggs to allow their eventual settlement on local reef structure. The prospects of recruitment on a distant reef are small because Palau is geographically isolated. The strong currents disperse the eggs by moving them offshore, away from predatory fish. However, the eggs may return to the coast about six hours later as they circulate with the currents in the wake eddy, which remains attached for a semidiurnal tidal cycle.

The larger, island-scale, $40 \mathrm{~km}$ diameter wake eddy may also play a role (Figures 1c and 6). Blue Corner is a dive site on the western barrier reef about $18 \mathrm{~km}$ distant from the south point. This area is known for its strong currents and very high fish populations. It is within the island-scale wake on another smaller submerged ridge.

Third, while El Niño produces $T$ changes of up to $10^{\circ} \mathrm{C}$ over one to two months (Qiu et al., 2019, in this issue; Schönau et al., 2019, in this issue), the lee waves described here heave the water column to produce peak-to-peak $T$ changes of $4^{\circ} \mathrm{C}$ over $1 \mathrm{~km}$ on tidal timescales. Elsewhere around Palau, similarly large $T$ variability is noted over short temporal and spatial scales due to topographic effects (Colin, 2018; Colin et al., 2019, in this issue).

\section{SUMMARY}

When a current encounters topography, it may go over or around the obstacle, producing lee waves and wake eddies that remove momentum and energy from the incident flow and transfer them to finer scales. Both waves and eddies are found at the same place and time at sloping submarine ridges (Warner and MacCready, 2009). As the NEC flows westward and around the south point of Peleliu Island, 
wake eddies are generated by a combination of mean and tidal flows at two spatial scales: (a) the submesoscale with a diameter of about $2 \mathrm{~km}$, which is determined by the tides, and (b) the island scale with a diameter of about $50 \mathrm{~km}$, which is about half the cross-stream width of the island and lagoon. Thus, at the largest scale, the lee side of the topography accommodates one cyclonic eddy from the north point and one anticyclonic eddy from the south point (in this case we consider the main lagoon as the topographic obstacle from Kayangel to Peleliu; Figure 1a). These eddies' radii depend on the topographic scale and are substantially less than the mesoscale, which is characterized by the Rossby or deformation radius of about $150 \mathrm{~km}$ near Palau. Zeiden et al. (2019) address an island-scale wake, while we focus on the submesoscale eddies created by a combination of tidal and mean flow similar to those at the north point of Velasco Reef observed by MacKinnon et al. (2019). These eddies are created as the westward tidal flow strengthens and are then released into the steady flow of the NEC as the tidal flow becomes eastward and the total flow approaches zero. Both the tidal flow and the steady flow have roughly equal magnitudes. Further variability in the incident flow arises due to the winds and is noted in the model. The detached eddies can then be detected up to $50 \mathrm{~km}$ away and may persist farther downstream. Oscillating flow from inertial motions is also likely important (Siegelman et al., 2019, in this issue), but our surveys were short compared to the inertial period of about four days.

As the westward current flows over the submarine ridge south of Peleliu, internal lee waves are created and extract energy and momentum from the current. If they dissipate where they are generated, that would account for the observed turbulent dissipation. The form drag exerted by the waves (i.e., upward transport of eastward momentum) in the upper portion of the water column is (a) much greater than the bottom drag, and (b) acts to decelerate the westward flow. However, the flow speed of $0.5 \mathrm{~m} \mathrm{~s}^{-1}$ moves the water over this high drag area of several kilometers in a few hours, which limits the impact of the drag. Nevertheless, the form drag at only one submarine ridge may have the same effect on slowing the incident flow as bottom drag along the entire coastline of Palau. There may be another four such submarine ridges around Palau. Numerical modeling indicates form drag due to eddies in the lee of the point and pressure drops across the submarine ridge can be an order of magnitude greater than the wave drag.

In summary, at the south point of Palau and over a distance of order $1 \mathrm{~km}$, energy cascades suddenly from a combination of tidal flow and the NEC (with spatial scales exceeding $100 \mathrm{~km}$ ) into wake eddies and lee waves of $1 \mathrm{~km}$ scale. Island-scale eddies are also noted. As the $1 \mathrm{~km}$ scale eddy circulates back to the south point, a front is produced between the incident flow and the water in the wake, which appear distinct. Water mass interleaving is found down to scales of $1-10 \mathrm{~m}$. At these fronts, turbulence is elevated on millimeter to centimeter scales. C

\section{REFERENCES}

Arbic, B.K., O.B. Fringer, J.M. Klymak, F.T. Mayer, D.S. Trossman, and P. Zhu. 2019. Connecting process models of topographic wave drag to global eddying general circulation models. Oceanography 32(4):146-155, https://doi.org/ 10.5670/oceanog.2019.420.

Blumberg, A.F., and G.L. Mellor. 1987. A description of a three-dimensional ocean circulation model. Pp. 1-16 in Three-dimensional Coastal Ocean Models. Coastal Estuarine Series vol. 4, N.S. Heaps, ed., American Geophysical Union, Washington, DC.

Chang, M.-H., T.Y. Tang, C.-R. Ho, and S.-Y. Chao.

2013. Kuroshio-induced wake in the lee of Green Island off Taiwan. Journal of Geophysical Research 118(3):1,508-1,519, https://doi.org/10.1002/ jgrc.20151.

Colin, P.L. Ocean warming and the reefs of Palau. 2018. Oceanography 31(2):126-135, https://doi.org/ 10.5670/oceanog.2018.214.

Colin, P.L., T.M.S. Johnston, J.A. MacKinnon, C.Y. Ou, D.L. Rudnick, E.J. Terrill, S.J. Lindfield, and H. Batchelor. 2019. Ngaraard Pinnacle, Palau: An undersea "Island" in the flow. Oceanography 32(4):164-173, https://doi.org/ 10.5670/oceanog. 2019.422

Cummings, J., and O. Smedstad. 2013. Variational data analysis for the global ocean. Pp. 303-343 in Data Assimilation for Atmospheric, Oceanic and Hydrologic Applications, vol. II. S. Park and L. Xu, eds, Springer-Verlag, https://doi.org/ 10.1007/978-3-642-35088-7_13.

D’Asaro, E.A. 1988. Generation of submesoscale vortices: A new mechanism. Journal of Geophysical Research 93(C6):6,685-6,693, https://doi.org/ 10.1029/JC093iC06p06685.
Davies, P.A., P. Besley, and D.L. Boyer. 1989. An experimental study of flow past a triangular cape in a linearly stratified fluid. Dynamics of Atmospheres and Oceans 14:497-528, https://doi.org/ 10.1016/0377-0265(89)90076-6.

Dewey, R.K., and W.R. Crawford. 1988. Bottom stress estimates from vertical dissipation rate profiles on the continental shelf. Journal of Physical Oceanography 18:1,167-1,177, https://doi.org/10.1175/1520-0485(1988)018 $<1167$ :BSEFVD>2.0.CO;2.

Dong, C., J.C. McWilliams, and A.F. Shchepetkin. 2007. Island wakes in deep water. Journal of Physical Oceanography 37:962-981, https://doi.org/10.1175/JP03047.1.

Egbert, G., and S. Erofeeva. 2002. Efficient inverse modeling of barotropic ocean tides. Journal of Atmospheric and Oceanic Technology 19(2):183-204, https://doi.org/10.1175 1520-0426(2002)019<0183:EIMOBO>2.0.CO;2.

Garrett, C. 1995. Flow separation in the ocean. Pp. 119-124 in Topographic Interactions in the Ocean: Proceedings of the Aha Huliko'a Workshop

Gill, A.E. 1982. Atmosphere-Ocean Dynamics. Academic Press, $662 \mathrm{pp}$

Gopalakrishnan, G., and B.D. Cornuelle. 2019. Palau's effects on regional-scale ocean circulation. Oceanography 32(4):126-135, https://doi.org/ 10.5670/oceanog.2019.418.

Gula, J., M.J. Molemaker, and J.C. McWilliams. 2016 Topographic generation of submesoscale centrifugal instability and energy dissipation. Nature Communications 7:12811, https://doi.org/10.1038/ ncomms12811.

Haley, P.J. Jr., and P.F.J. Lermusiaux. 2010. Multiscale two-way embedding schemes for free-surface primitive equations in the "Multidisciplinary Simulation, Estimation and Assimilation System." Ocean Dynamics 60(6):1,497-1,537, https://doi.org/ 10.1007/s10236-010-0349-4.

Haley, P.J. Jr., A. Agarwal, and P.F.J. Lermusiaux. 2015. Optimizing velocities and transports for complex coastal regions and archipelagos. Ocean Modelling 89:1-28, https://doi.org/10.1016/j.ocemod. 2015.02.005.

Johnston, T.M.S., M.C. Schönau, T. Paluszkiewicz, J.A. MacKinnon, B.K. Arbic, P.L. Colin, M.H. Alford, M. Andres, L. Centurioni, H.C. Graber, and others. 2019. Flow Encountering Abrupt Topography (FLEAT): A multiscale observational and modeling program to understand how topography affects flows in the western North Pacific. Oceanography 32(4):10-21, https://doi.org/10.5670/ oceanog.2019.407.

Karnauskas, M., L.M. Chérubin, and C.B. Paris 2011. Adaptive significance of the formation of multi-species fish spawning aggregations near submerged capes. PLoS ONE 6(7):e22067, https://doi.org/10.1371/journal.pone.0022067.

Kundu, P.K., and I.M. Cohen. 2002. Fluid Mechanics. Academic Press, 730 pp.

Leslie, W.G., P.J. Haley Jr., P.F.J. Lermusiaux, M.P. Ueckermann, O. Logutov, and J. Xu. 2010. MSEAS Manual. MSEAS Report 06, Department of Mechanical Engineering, Massachusetts Institute of Technology, Cambridge, MA

Logutov, O.G., and P.F.J. Lermusiaux. 2008. Inverse barotropic tidal estimation for regional ocean applications. Ocean Modelling 25(1-2):17-34 https://doi.org/10.1016/j.ocemod.2008.06.004.

Lucas, A.J., J.D. Nash, R. Pinkel, J.A. MacKinnon, A. Tandon, A. Mahadevan, M. Omand, M. Frielich, D. Sengupta, M. Ravichandran, and others. 2016. Adrift upon a salinity-stratified sea: A view of upper ocean processes in the Bay of Bengal during the southwest monsoon. Oceanography 29(2):134-145 https://doi.org/10.5670/oceanog.2016.46.

MacKinnon, J.A., and M.C. Gregg. 2003. Mixing on the late-summer New England Shelf: Solibores, shear, and stratification. Journal of Physical 
Oceanography 33:1,476-1,492, https://doi.org/ 10.1175/1520-0485(2003)033<1476:MOTLNE> 2.0.CO;2.

MacKinnon, J.A., M.H. Alford, G. Voet, K. Zeiden, T.M.S. Johnston, M. Siegelman, S. Merrifield, and M. Merrifield. 2019. Eddy wake generation from broadband currents near Palau. Journal of Geophysical Research 124(7):4,891-4,903, https://doi.org/10.1029/2019JC014945.

Magaldi, M., T. Özgökmen, A. Griffa, E. Chassignet, M. Iskandarani, and H. Peters. 2008. Turbulent flow regimes behind a coastal cape in a stratified and rotating environment. Ocean Modelling 25(1):65-82, https://doi.org/10.1016/ j.ocemod.2008.06.006.

McCabe, R.M., P. MacCready, and G. Pawlak. 2006. Form drag due to flow separation at a headland. Journal of Physical Oceanography 36(11):2,136-2,152, https://doi.org/10.1175/JPO2966.1.

Merrifield, S.T., P.L. Colin, T. Cook, C. GarciaMoreno, J.A. MacKinnon, M. Otero, T.A. Schramek, M. Siegelman, H.L. Simmons, and E.J. Terrill. 2019 Island wakes observed from high-frequency current mapping radar. Oceanography 32(4):92-101, https://doi.org/10.5670/oceanog.2019.415.

Moum, J.N., M.C. Gregg, R.C. Lien, and M.E. Carr 1995. Comparison of turbulent kinetic energy dissipation rate estimates from two ocean microstructure profilers. Journal of Atmospheric and Oceanic Technology 12:346-366, https://doi.org/10.1175/ 520-0426(1995)012<0346:COTKED>2.0 Co:2.

Moum, J.N., and J.D. Nash. 2000. Topographically induced drag and mixing at a small bank on the continental shelf. Journal of Physical Oceanography 30:2,049-2,054, https://doi.org/ 10.1175/1520-0485(2000)030<2049:TIDAMA> 2.0.CO;2.

Musgrave, R.C., and T. Peacock. 2016. The momentum balance of steady flow past an island. Paper presented at the $\mathrm{VIII}{ }^{\text {th }}$ International Symposium on Stratified Flows, August 29-September 1, 2016, San Diego, CA.

Nash, J.D., J. Marion, N. McComb, J.S. Nahorniak, R.H. Jackson, C. Perren, D. Winters, A. Pickering, J. Bruslind, L. Yong, and S.J.K. Lee. 2017. Autonomous CTD profiling from the Robotic Oceanographic Surface Sampler. Oceanography 30(2)110-112, https://doi.org/10.5670/oceanog.2017.229.

Perlin, A., J.N. Moum, J. Klymak, M.D. Levine T. Boyd, and M. Kosro. 2005. A modified law-ofthe-wall applied to oceanic bottom boundary layers. Journal of Geophysical Research 110(C10), https://doi.org/10.1029/2004JC002310.

Pinkel, R., M.A. Goldin, J.A. Smith, O.M. Sun, A.A. Aja, M.N. Bui, and T. Hughen. 2011. The Wirewalker: A vertically profiling instrument carrier powered by ocean waves. Journal of Atmospheric and Oceanic Technology 28(3):426-435, https://doi.org/10.1175/ 2010JTECHO805.1.

Qiu, B., D.L. Rudnick, I. Cerovecki, S. Chen, M.C. Schönau, J.L. McClean, and G. Gopalakrishnan. 2015. The Pacific North Equatorial Current: New insights from the origins of the Kuroshio and Mindanao Currents (OKMC) Project. Oceanography 28(4):24-33, https://doi.org/ 10.5670/oceanog.2015.78.

Qiu, B., S. Chen, B.S. Powell, P.L. Colin, D.L. Rudnick, and M.C. Schönau. 2019. Nonlinear short-term upper ocean circulation variability in the tropical western Pacific. Oceanography 32(4):22-31, https://doi.org/10.5670/oceanog.2019.408.

Rudnick, D.L., and J.R. Luyten. 1996. Intensive surveys of the Azores Front: Part 1. Tracers and dynamics. Journal of Geophysical Research 101(C1):923-939, https://doi.org/10.1029/95JC02867.

Rudnick, D.L., and J. Klinke. 2007. The underway conductivity-temperature-depth instrument. Journal of Atmospheric and Oceanic Technology 24:1,910-1,923, https://doi.org/10.1175/ JTECH2100.1.
Rudnick, D.L., K.L. Zeiden, C.Y. Ou, T.M.S. Johnston, J.A. MacKinnon, M.H. Alford, and G. Voet. 2019. Understanding vorticity caused by flow passing an island. Oceanography 32(4):66-73, https://doi.org/ 10.5670/oceanog. 2019.412.

Sadovy de Mitcheson, Y., and P.L. Colin, eds. 2012 Reef Fish Spawning Aggregations: Biology, Research and Management. Fish and Fisheries, vol. 35, Springer Netherlands, https://doi.org/ 10.1007/978-94-007-1980-4.

Schönau, M.C., and D.L. Rudnick. 2015. Glider observations of the North Equatorial Current in the western tropical Pacific. Journal of Geophysical Research 120:3,586-3,605, https://doi.org/ 10.1002/2014JC010595.

Schönau, M.C., H.W. Wijesekera, W.J. Teague, P.L. Colin, G. Gopalakrishnan, D.L. Rudnick, B.D. Cornuelle, Z.R. Hallock, and D.W. Wang. 2019. The end of an El Niño: A view from Palau. Oceanography 32(4):32-45, https://doi.org/ 10.5670/oceanog.2019.409.

Schramek, T.A., P.L. Colin, M.A. Merrifield, and E.J. Terrill. 2018. Depth-dependent thermal stress around corals in the tropical Pacific Ocean. Geophysical Research Letters 45:9,739-9,747, https://doi.org/10.1029/2018GL078782.

Schramek, T.A., B.D. Cornuelle, G. Gopalakrishnan, P.L. Colin, S.J. Rowley, M.A. Merrifield, and E.J. Terrill. 2019. Tropical western Pacific thermal structure and its relationship to ocean surface variables: A numerical state estimate and forereef temperature records. Oceanography 32(4):156-163, https://doi.org/10.5670/oceanog.2019.421.

Siegelman, M., M.A. Merrifield, E. Firing, J.A. MacKinnon, M.H. Alford, G. Voet, H.W. Wijesekera, T.A. Schramek, K.L. Zeiden, and E.J. Terrill. 2019. Observations of near-inertial surface currents at Palau. Oceanography 32(4):74-83, https://doi.org/10.5670/oceanog.2019.413.

Signell, R.P., and W.R. Geyer. 1991. Transient eddy formation around headlands. Journal of Geophysical Research 96(C2):2,561-2,575, https://doi.org/ 10.1029/90JC02029.

Simmons, H.L., B.S. Powell, S.T. Merrifield, S.E. Zedler, and P.L. Colin. 2019. Dynamical downscaling of equatorial flow response to Palau. Oceanography 32(4):84-91, https://doi.org/ 10.5670/oceanog.2019.414.

Trossman, D.S., B.K. Arbic, J.G. Richman, S.T. Garner, S.R. Jayne, and A.J. Wallcraft. 2016. Impact of topo graphic internal lee wave drag on an eddying global ocean model. Ocean Modelling 97:109-128, https://doi.org/10.1016/j.ocemod.2015.10.013.

Ueckermann, M.P., and P.F.J. Lermusiaux. 2012 2.29 Finite Volume MATLAB Framework Documentation. MSEAS Report 14, Department of Mechanical Engineering, Massachusetts Institute of Technology, Cambridge, MA.

Ueckermann, M.P., and P.F.J. Lermusiaux. 2016. Hybridizable discontinuous Galerkin projection methods for Navier-Stokes and Boussinesq equations. Journal of Computational Physics 306:390-421, https://doi.org/10.1016/ j.jcp.2015.11.028.

Warner, S.J., and P. MacCready. 2009. Dissecting the pressure field in tidal flow past a headland: When is form drag "real"? Journal of Physical Oceanography 39:2,971-2,984, https://doi.org/ 10.1175/2009JPO4173.1.

Wijesekera, H.W., E. Jarosz, W.J. Teague, D.W. Wang, D.B. Fribance, J.N. Moum, and S.J. Warner. 2014 Measurements of form and frictional drags over a rough topographic bank. Journal of Physical Oceanography 44:2,409-2,432, https://doi.org/ 10.1175/JPO-D-13-0230.1

Wolanski, E., J. Imberger, and M. Heron. 1984 Island wakes in shallow coastal waters. Journal of Geophysical Research 89(C6):10,553-10,569, https://doi.org/10.1029/JC089iC06p10553.

Zedler, S.E., B.S. Powell, B. Qiu, and D.L. Rudnick 2019. Energy transfer in the western tropical Pacific. Oceanography 32(4):136-145, https://doi.org/10.5670/oceanog.2019.419.
Zeiden, K.L., D.L. Rudnick, and J.A. MacKinnon. 2019. Glider observations of a mesoscale oceanic island wake. Journal of Physical Oceanography 49(9):2,217-2,235, https://doi.org/10.1175/ JPO-D-18-0233.1.

\section{ACKNOWLEDGMENTS}

We are grateful to Terri Paluszkiewicz at the Office of Naval Research for leading the Flow Encountering Abrupt Topography (FLEAT) initiative; Captain David Murline, crew, and scientists on R/V Roger Revelle, and the staff of the Coral Reef Research Foundation for their help in carrying out the field program; and our colleagues in FLEAT for their collaboration. We wish to thank the Bureau of Marine Resources, Ministry of Natural Resources, Environment and Tourism of the Palau National Government, and the Peleliu State Government for the relevant permits to conduct this research in Palau's waters. This work was funded by grants N00014-13-1-0480, N00014-151-2320, and N00014-15-1-2843 (TMSJ, CYO); N00014 15-1-2264 (JAM, AFW); and N00014-15-1-2626 (PFJL, PJH). We thank two anonymous reviewers for their helpful comments.

\section{AUTHORS}

T.M. Shaun Johnston (tmsjohnston@ucsd.edu) is Associate Research Oceanographer, and Jennifer A. MacKinnon is Professor and Associate Dean, both at Scripps Institution of Oceanography, University of California San Diego (SIO-UCSD), La Jolla, CA, USA. Patrick L. Colin is Director, Coral Reef Research Foundation, Koror, Palau. Patrick J. Haley Jr. is Research Scientist and Pierre F.J. Lermusiaux is Professor, both in the Department of Mechanical Engineering, Massachusetts Institute of Technology (MIT), Cambridge, MA, USA. Andrew J. Lucas is Assistant Professor, Mark A. Merrifield is Professor and Director, Center for Climate Change Impacts and Adaptation, and Sophia T. Merrifield is Assistant Project Scientist, all at SIO-UCSD, La Jolla, CA, USA Chris Mirabito is Research Associate, Department of Mechanical Engineering, MIT, Cambridge, MA, USA. Jonathan D. Nash is Professor, College of Earth, Ocean and Atmospheric Sciences, Oregon State University, Corvallis, OR, USA. Celia Y. Ou is a PhD candidate at SIO-UCSD, La Jolla, CA, USA. Mika Siegelman is a PhD candidate in the School of Ocean and Earth Science and Technology, University of Hawai'i at Mānoa, Honolulu, HI, USA. Eric J. Terrill is Director, Coastal Observing Research and Development Center, and Amy F. Waterhouse is Associate Project Scientist, SIO-UCSD, La Jolla, CA, USA.

\section{ARTICLE CITATION}

Johnston, T.M.S., J.A. MacKinnon, P.L. Colin, P.J. Haley Jr., P.F.J. Lermusiaux, A.J. Lucas, M.A. Merrifield, S.T. Merrifield, C. Mirabito, J.D. Nash, C.Y. Ou, M. Siegelman, E.J. Terrill, and A.F. Waterhouse. 2019. Energy and momentum lost to wake eddies and lee waves generated by the North Equatorial Current and tidal flows at Peleliu, Palau. Oceanography 32(4):110-125, https://doi.org/10.5670/ oceanog. 2019.417

\section{COPYRIGHT \& USAGE}

This is an open access article made available under the terms of the Creative Commons Attribution 4.0 International License (https://creativecommons.org/ licenses/by/4.0/), which permits use, sharing, adaptation, distribution, and reproduction in any medium or format as long as users cite the materials appropriately, provide a link to the Creative Commons license, and indicate the changes that were made to the original content. 